\title{
MicroRNAs and obesity-induced endothelial dysfunction: key paradigms in molecular therapy
}

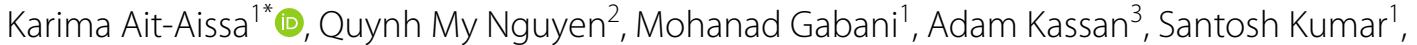 \\ Soo-Kyoung Choi ${ }^{4}$, Alexis A. Gonzalez ${ }^{5}$, Tahsin Khataei ${ }^{1}$, Amal M. Sahyoun ${ }^{6}$, Cheng Chen ${ }^{7}$ and Modar Kassan ${ }^{\text {* }}$
}

\begin{abstract}
The endothelium plays a pivotal role in maintaining vascular health. Obesity is a global epidemic that has seen dramatic increases in both adult and pediatric populations. Obesity perturbs the integrity of normal endothelium, leading to endothelial dysfunction which predisposes the patient to cardiovascular diseases. MicroRNAs (miRNAs) are short, single-stranded, non-coding RNA molecules that play important roles in a variety of cellular processes such as differentiation, proliferation, apoptosis, and stress response; their alteration contributes to the development of many pathologies including obesity. Mediators of obesity-induced endothelial dysfunction include altered endothelial nitric oxide synthase (eNOS), Sirtuin 1 (SIRT1), oxidative stress, autophagy machinery and endoplasmic reticulum (ER) stress. All of these factors have been shown to be either directly or indirectly caused by gene regulatory mechanisms of miRNAs. In this review, we aim to provide a comprehensive description of the therapeutic potential of miRNAs to treat obesity-induced endothelial dysfunction. This may lead to the identification of new targets for interventions that may prevent or delay the development of obesity-related cardiovascular disease.
\end{abstract}

Keywords: MicroRNAs, Obesity, Endothelial dysfunction, Cardiovascular diseases

\section{Background}

Obesity is a major worldwide public health issue [1]. In the past decade, the incidence of obesity has rapidly risen to epidemic proportions $[2,3]$. In the United States, obesity continues to be one of the leading public health crises. Almost a third of the American population is affected by obesity (Body mass index $(\mathrm{BMI})>30$ ), and $60 \%$ fall into the overweight category $(\mathrm{BMI}>25)[4$, 5]. It is crucial to address and treat obesity because it is classified as a risk factor in the development of cardiovascular disease [6]. Diverse mechanisms by which obesity promotes cardiovascular disease have been proposed,

\footnotetext{
*Correspondence: karima-ait-aissa@uiowa.edu; modar-kassan@uiowa.edu

${ }^{1}$ Cardiovascular Division, Department of Medicine, and Abboud

Cardiovascular Research Center, University of lowa Carver College of Medicine, lowa City, IA 52242, USA

Full list of author information is available at the end of the article
}

and most involve endothelial dysfunction [7]. Vascular function assessments in subjects with obesity have demonstrated altered properties of endothelial function $[8,9]$. Many studies have established that endothelial dysfunction can be considered as the first step in the progression of cardiovascular disease [10-13]. Thus, a better understanding of the mediators of obesity-induced endothelial dysfunction will help us to identify new targets for interventions that may prevent or postpone the development of obesity-related cardiovascular disease.

MicroRNAs (miRNAs) are noncoding small RNAs that play a central role in a wide range of biological cellular functions [14]. Altered microRNA expression has been reported in association with many different human diseases such as cancer, neurodevelopmental, metabolic, and cardiovascular diseases $[15,16]$. Dysregulation of microRNAs affects the status and functions of different tissues and organs, including the endothelial dysfunction 
that leads to obesity-induced cardiovascular diseases. In this review, we will first begin by revising the biogenesis, regulation and mechanism of action of miRNAs. Then, we will illustrate the importance of miRNAs as modulators of endothelial function, and we will address the role of miRNAs in obesity-induced endothelial dysfunction.

\section{MicroRNAs}

MiRNAs are small (18-25 nucleotides (nt)), singlestranded and non-coding RNA molecules that play important roles in multiple cellular processes such as differentiation, proliferation, apoptosis, stress response. Their alteration contributes to the development of many pathologies including obesity [17]. After the discovery of the first miRNA, lin-4, in Caenorhabditis elegans in 1993 [18], researchers have since demonstrated that these small molecules are an abundant class of RNAs in all prokaryotic and eukaryotic cells $[19,20]$. To date, 2654 human miRNAs have been uncovered [21] and each single miRNA can regulate the expression of several different genes. Additionally, different miRNAs can cooperatively regulate the expression of a target gene. This fact exposes the high complexity of the regulatory network constituted by the miRNAs and their targets [22]. In mammals, miRNAs can bind, either partially or totally, to the $3^{\prime}$ UTR regions of a wide variety of mRNAs in order to prevent their translation into proteins or induce their degradation [20] (Fig. 1).

\section{MiRNAs biogenesis, regulation, and mechanism of action} While most of the gene-encoding miRNAs are incorporated into the genome and are expressed using their own promoter, a minority are located within the introns and are transcribed as part of the annotated genes [20]. During miRNA biogenesis, the gene-encoding miRNA transcription is mediated mainly by RNA polymerase II (Pol II) and to a lesser extent by RNA polymerase III (Pol III), producing RNA precursors named pri-miRNAs. These pri-miRNAs are accessorized with their own CAP and poly-A tail, at $5^{\prime}$ and $3^{\prime}$ endpoints, respectively [23]. Every pri-miRNA contains a stem $(\sim 33 \mathrm{pb})$, a terminal loop, and a single-stranded RNA segment (ssRNA) [23, $24]$. The pri-miRNAs then enter the maturation process where two ribonuclease-mediated reactions are required [20]. The process begins in the nucleus, where it is mediated by Drosha, a RNase type III protein; afterward, the process moves to the cytoplasm where it is mediated by Dicer, a type III endoribonuclease [25]. In the nucleus,

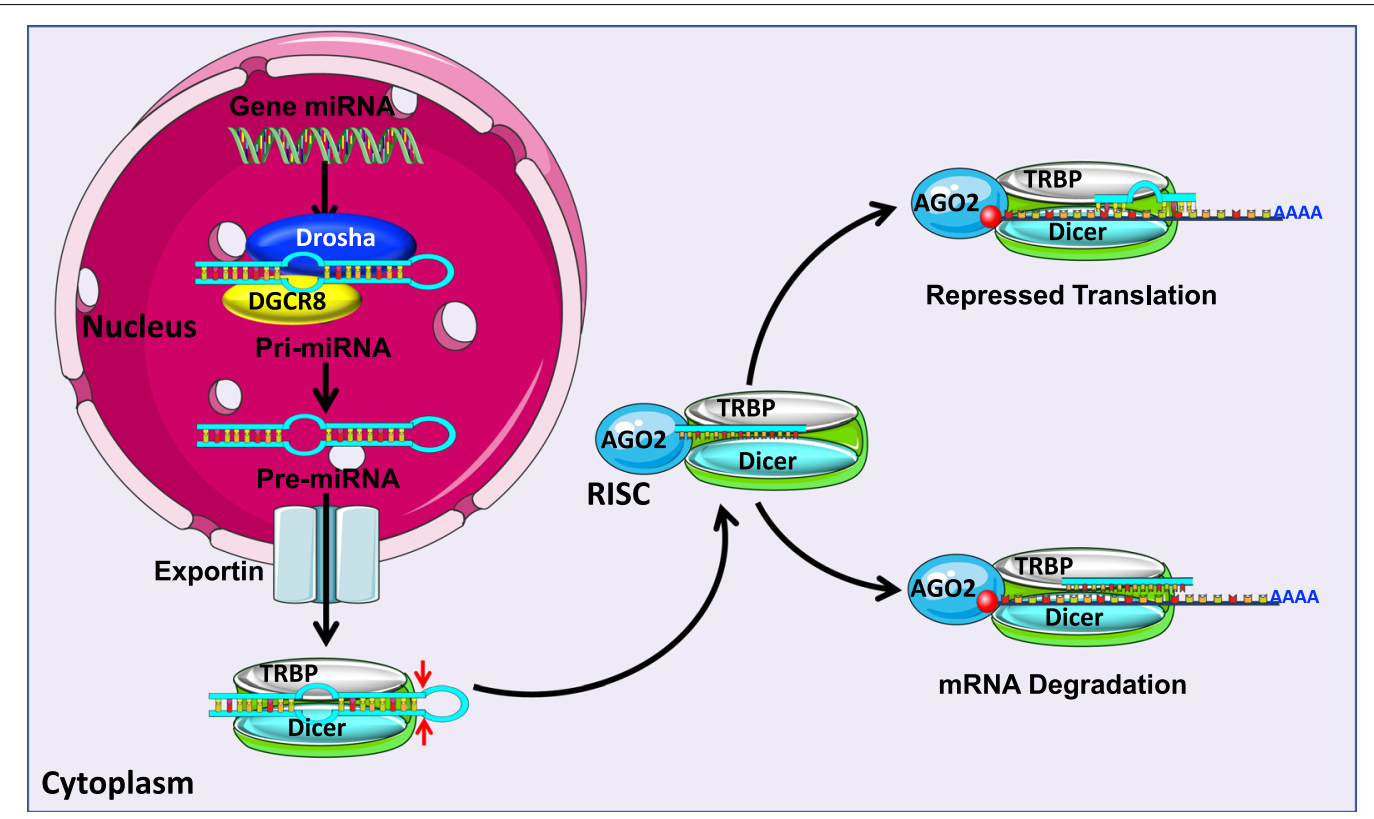

Fig. 1 Summarized scheme of miRNAs biogenesis and mechanism of action: In the nucleus, Pol II and Pol III RNA polymerases transcribe the coding sequences of miRNAs. Drosha binds to DGCR8 cofactor to catalyze the formation of pre-miRNA. Pre-miRNA is then translocated by the exportins system from the nucleus to the cytoplasm, where it is then cleaved by the Dicer-TRBP complex to form a 22nt-dsRNA. Within the cytoplasm, the 22nt-dsRNA interacts with AGO proteins to form the RISC complex, while the passenger strand is degraded. The 22nt-RNA guide chain constitutes a mature miRNA that guides the RISC complex towards the 3-UTR regions of the mRNA targets. This interaction either represses their translation or induces their degradation. Pol: polymerase; Drosha: ribonuclease III double-stranded RNA-specific endoribonuclease; DGCR8: DiGeorge syndrome chromosomal region 8; Dicer: helicase with RNase motif; TRBP: TAR RNA binding protein; AGO: Argonaute protein; RISC: RNA-induced silencing complex; UTR: untranslated region 
Drosha binds to Di George Syndrome Critical Region Gene 8 (DGCR8) cofactor to form a complex known as a microprocessor $[25,26]$. The DGCR8 part of this complex then binds to pri-miRNA' s stem and loop structure, allowing Drosha to catalyze the breaking of the double strand of RNA in the stem. This cleavage induces the release of a fragment of $70 \mathrm{nt}$ with hairpin structure called precursor miRNA (Pre-miRNA) [27, 28]. Following this, Exportin-5 and its cofactor, Ras-related nuclear Guanine nucleotide-binding proteins (Ran-GTP) export the newly formed pre-miRNAs to the cytoplasm where the second reaction of the maturation process takes place [29]. In the cytoplasm, Dicer cleaves the pre-miRNAs near the terminal loop structure, creating a doublestranded miRNA (dsRNA) fragment of approximately 22 nt [30]. Dicer additionally interacts with TAR RNA-binding protein (TRBP), contributing to the formation of the RNA-Inducing Silencing Complex (RISC) [31-33]. The newly formed 22 nt- dsRNA binds to the protein Argonaute (Ago) to generate the effector complex, RISC. The guide RNA chain of $22 \mathrm{nt}$ remains in the RISC complex as a mature miRNA, while the transient chain is degraded in some cases [29]. Next, the seed sequence of the mature miRNA facilitates specific recognition of the 3-UTR regions of the target mRNAs by guiding the RISC effector complex to recognize the target mRNA and negatively signal its expression. When the complementarity of sequences between the seed sequence of the miRNA and the 3-UTR region of the target mRNA is imperfect, ribosomal access to the mRNA is blocked, thereby repressing translation. On the other hand, when the complementarity is perfect, the target mRNA is degraded [30] (Fig. 1).

\section{Obesity, microRNAs and endothelial dysfunction}

The endothelium, a monolayer of endothelial cells (ECs) coating the vascular lumen, is the first point of contact between the blood components and the vascular wall [34-36]. Under physiological conditions, the endothelium is able to respond to physical and chemical stimuli by releasing several different factors that play key roles in regulating cellular adhesion, thromboresistance, smooth muscle cell proliferation, inflammation, and vascular tone $[37,38]$. Of particular note, the endothelium responds to changes in blood flow or chemical agents by releasing molecules that induce the vessel to relax or constrict [35]. Some of these molecules, such as nitric oxide (NO), possesses vasodilatory properties [37], while others, such as endothelin [39], are vasoconstrictors. By regulating vessel tone and diameter, this vasomotion is directly involved in balancing oxygen supply with the metabolic demands of tissues [40]. The imbalance between vasoconstrictor and vasodilatory markers is a notable feature of cardiovascular diseases and will lead to vascular endothelial dysfunction [41].

Clinical studies have shown that patients with obesity display lower levels of NO bioavailability, leading to impairment of endothelium-dependent vasodilation [42]. These studies have established that decreased expression of endothelial nitric oxide synthase (eNOS), the enzyme responsible for NO production in the endothelium, is the major cause for endothelial dysfunction in obesity [8].

Furthermore, evidence indicates that the enzyme NAD-dependent deacetylase sirtuin-1 (SIRT1), which deacetylates proteins that contribute to cellular regulation during stress, plays a pivotal role in endothelial homeostasis by increasing eNOS gene expression [43]. Interestingly, SIRT1 has been found to be reduced during obesity, thereby leading to endothelial dysfunction [44].

Obesity has additionally been shown to induce several cellular stresses that impair endothelial function. These major stresses include oxidative stress [45], endoplasmic reticulum (ER) stress [46, 47], autophagy disruption [48], and inflammation [49]. All these stressors have been shown to decrease NO bioavailability during obesity and as a consequence, lead to endothelial dysfunction [49] (Fig. 2).

Recently, in vitro and in vivo studies have established that miRNAs are crucial for ECs gene expression, regulation and function in various pathological conditions including obesity $[17,50,51]$. In this review, we will provide an overview of the miRNA role in controlling the key connecting mechanism between endothelial dysfunction and obesity.

\section{Endothelial nitric oxide synthase and miRNAs}

In the endothelium, NO is synthesized through the activation of eNOS [37]. Calcium $\left(\mathrm{Ca}^{2+}\right)$ entry into the ECs activates eNOS, which then transforms L-arginine into L-citrulline, leading to $\mathrm{NO}$ production. $\mathrm{NO}$ will diffuse from the ECs to the smooth muscle cells where it activates the soluble guanylate cyclase and increases the levels of cyclic guanosine monophosphate (cGMP) thereby causing vasodilatation. A major contributing factor to decreased NO bioavailability is the downregulation of eNOS mRNA expression [37].

MiRNAs have been shown to play an important role in regulating eNOS [52]. Therefore, we can consider that a loss of eNOS RNA messenger during obesity $[8,53]$ may be due to a change in miRNA profile during obesity. In this section, we will discuss further the interplay between miRNAs and eNOS in the context of obesity-induced endothelial dysfunction (Fig. 3).

Recent evidences have established the important role of miR-24 in regulating eNOS in the vasculature [5457]. Interestingly, miR-24 is well known to be increased 


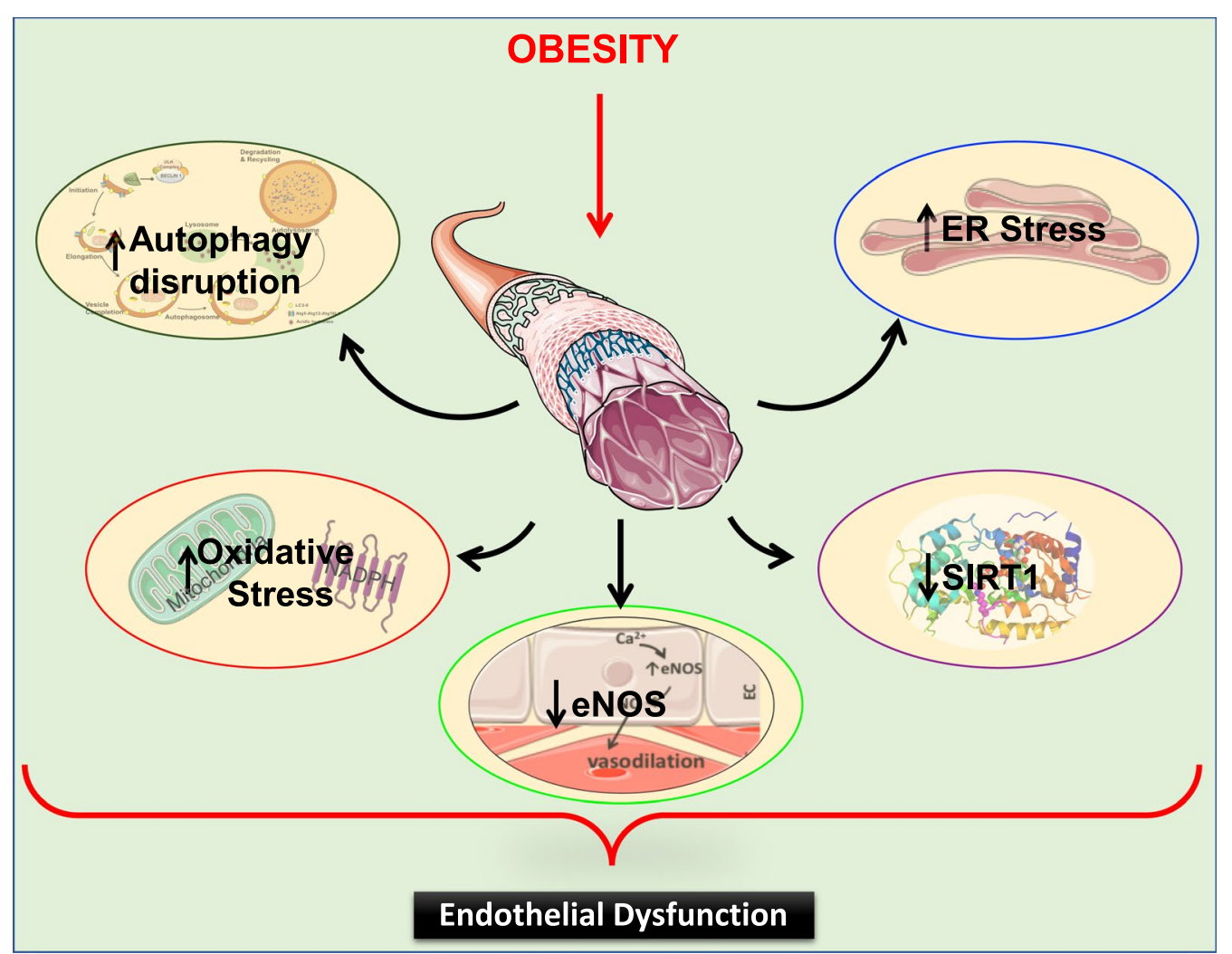

Fig. 2 Obesity induces endothelial dysfunction. Obesity induces a decrease in NO bioavailability by: reducing eNOS activation and/or expression; negatively regulating SIRT1; and inducing cellular stresses including oxidative stress, ER stress and autophagy disruption. All of these effects lead to endothelial dysfunction. NO: Nitric Oxide; eNOS: endothelial Nitric Oxide Synthase; SIRT1: Sirtuin 1; ER: endoplasmic reticulum

during obesity in diverse tissues including abdominal adipose tissue [58], liver [59] and hypothalamus [60]. Although there are no published studies investigating the role of miR-24 in ECs during obesity, in vitro studies have demonstrated that miR-24 significantly inhibits ECs proliferation and eNOS gene expression [54]. It is well known that endothelial dysfunction underlies the relationship between obesity and atherosclerosis [61]. eNOS deficiency accelerates atherosclerotic lesion formation in mice [62]. Similarly, miR-24 exacerbates atherogenesis and promote atheromatous plaque formation [63]. These findings suggest that further exploration of obesityinduced miR-24 upregulation may yield new therapeutic strategies for obesity-induced endothelial dysfunction.

MiR-155 has been described as an essential regulator of eNOS expression and endothelial function [64], and its inhibition is suggested to be a useful approach for restoring endothelial function during the development of cardiovascular diseases [64]. Interestingly, higher levels of miR-155 expression have been exhibited in adipose and kidney tissue from mice and patients with obesity $[65,66]$. In addition, miR-155 deletion abolished high fat diet (HFD)-induced adipocyte hypertrophy and inflammation, [65] indicating a detrimental role of miR155 in obesity. ECs pretreated with Tumor Necrosis Factor (TNF)- $\alpha$, known to be increased during obesity, displayed higher levels of miR-155 [67]. Moreover, TNF- $\alpha$ has been shown to play an important role in endothelial dysfunction during obesity [68] and metabolic diseases [69]. All together, these studies suggest a potential therapeutic for miR-155 inhibition in obesity-induced cardiovascular diseases.

Among the miRNAs that have been shown to play a direct role in regulating eNOS are miR-15b and miR-16 [70]. Expressed in ECs, these miRNAs interact directly with eNOS by targeting its mRNA at 3UTR [70]. Interestingly, these two miRNAs are known to be increased in obesity [71, 72]. Inhibition of miR-15b reduced hepatic insulin resistance in obesity [71], while inhibition of miR-16 decreased inflammation [73]. Both insulin resistance and inflammation are frequently associated with endothelial dysfunction and have been proposed to play a major role in cardiovascular diseases $[49,74]$. Although further studies are needed, these findings suggest that miR-15b and miR-16 inhibition in animal models or patients with obesity will protect 


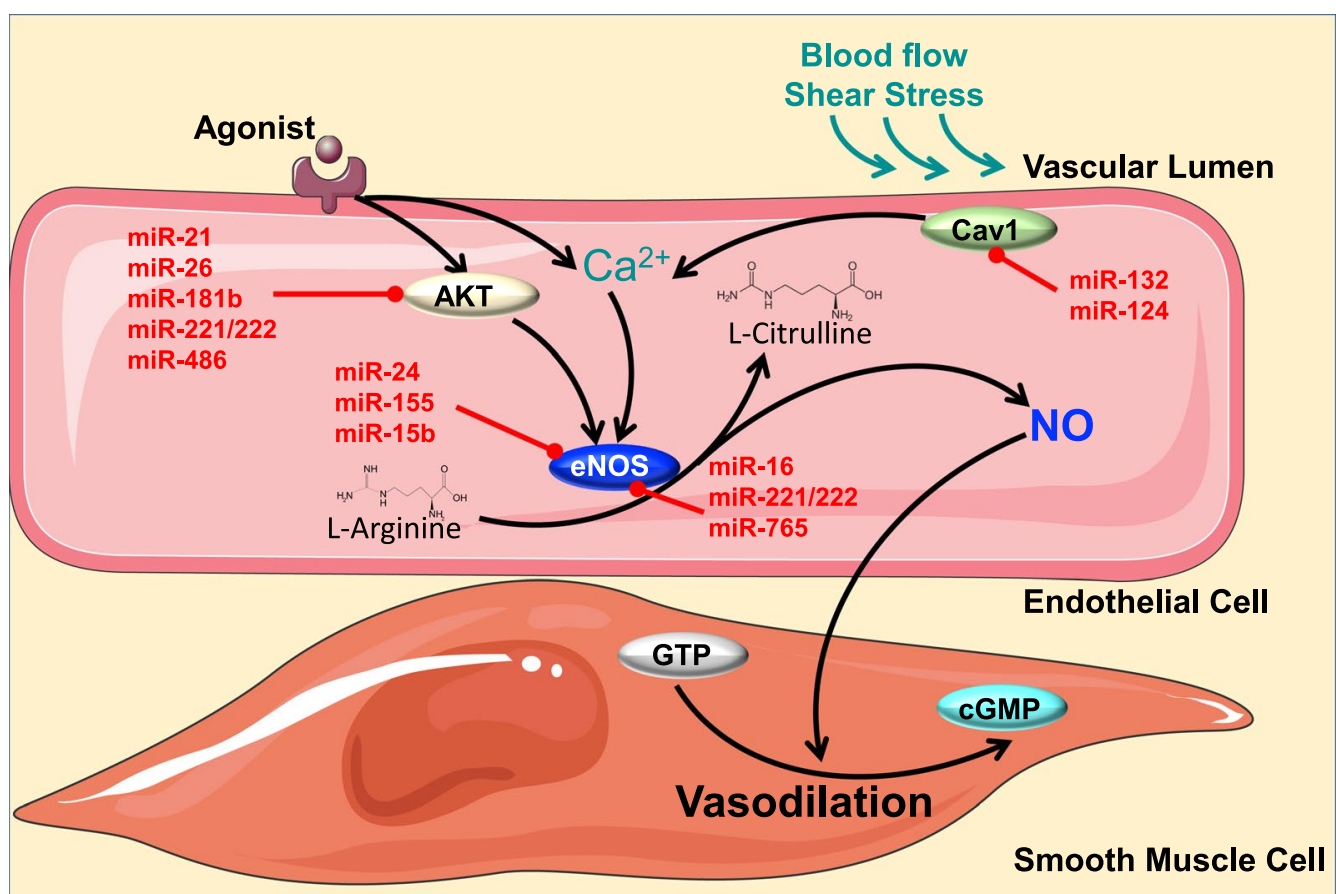

Fig. 3 Obesity, eNOS, miRNAs and endothelial function. Ca ${ }^{2+}$ activates eNOS which then converts L-Arginine to L-Citrulline, producing NO as a byproduct. NO, synthetized through eNOS phosphorylation in the endothelium, will diffuse to the smooth muscle cells and increase the levels of cGMP, which then induce vasodilatation. During obesity, higher levels of miR-24, miR-155, miR-15b, miR-16, miR-221/222 and miR-765 are expressed and directly inhibit eNOS translation, thereby causing endothelial dysfunction. Other miRNAs have been shown to affect eNOS through indirect signaling pathways such as AKT (miR-21, miR-26, miR-221/222, and miR-486) and Caveolin1 (miR-132 and miR-124). eNOS: endothelial Nitric Oxide Synthase; NO: Nitric Oxide; cGMP: cyclic guanosine monophosphate; Cav1: Caveolin 1; AKT: Protein kinase B

against eNOS mRNA degradation and can potentially prevent obesity-induced vascular dysfunction.

Another key player in vascular endothelial biology is miR-221/222, which is known to directly target eNOS [75]. Expression of this miRNA is upregulated in ECs during atherosclerosis and obesity [75]. In particular, it has been shown that miR-221/222 downregulates eNOS expression, leading to lower NO production in the vasculature during atherosclerosis [75]. Thus, inhibiting miR-221/222 could have clinical therapeutic effect in patients with obesity.

Finally, miR-765, the most abundant miRNAs detected in ECs [76], is known to bind directly to eNOS mRNA, leading to the mRNA's destabilization $[76,77]$. Patients with coronary artery disease display high levels of circulatory miR-765, suggesting its role as a biomarker for coronary artery disease [78]. Although this study did not directly correlate miR-765 to obesity, a diversity of evidences has demonstrated that obesity is highly associated to coronary artery disease [79-81]. Therefore, the assessment of miR-765 changes in ECs during obesity would be an interesting step to consider in the pursuit of therapeutic approaches against obesity-induced endothelial dysfunction (Table 1).

Other miRNAs have been shown to affect eNOS through indirect signaling pathways such as Protein kinase B (AKT) (miR-21, miR-26, miR-181b, miR221/222, and miR-486) [82, 83] and Caveolin1 (miR-132 and miR-124) [84-86]. However, in this review, we have discussed only those miRNAs that directly affect eNOS.

\section{Sirtuin 1 and miRNAs}

Sirtuin 1 (SIRT 1) is a member of a class III histone deacetylase family proteins (HDACs) dependent on nicotinamide adenine dinucleotide $\left(\mathrm{NAD}^{+}\right)$[87]. SIRT1 deacetylates histone proteins in addition to transcription factors and cofactors involved in gene regulation [88]. SIRT1 is considered the major metabolic regulator because of its ability to regulate several factors involved in energy homeostasis $[89,90]$. Recent evidence supports the idea that SIRT1, which is highly expressed in ECs, plays an important role in the regulation of endothelial function [91, 92]. In fact, SIRT1 is involved in regulating reactive oxygen species (ROS) production, increasing 
Table 1 MiRNA regulation during obesity, their function in the cardiovascular system and their potential targets in endothelial cells (eNOS)

\begin{tabular}{|c|c|c|c|c|c|c|}
\hline miRNA & $\begin{array}{l}\text { Up/downregulation } \\
\text { (obesity) }\end{array}$ & Refs. & Function & Refs. & Target & Refs. \\
\hline miR-24 & Up & {$[58-60]$} & Exacerbates atherogenesis and plaque formation & {$[62,63]$} & eNOS & {$[54-57]$} \\
\hline miR-155 & Up & {$[65,66]$} & Adipocytes hypertrophy and inflammation & [65] & eNOS & {$[64]$} \\
\hline miR-15b & Up & {$[71,72]$} & Hepatic insulin resistance & [71] & eNOS & [70] \\
\hline miR-16 & Up & {$[71,72]$} & Increases inflammation & [73] & eNOS & [70] \\
\hline miR-221/222 & Up & [75] & Increases atherosclerosis & [75] & eNOS & {$[75]$} \\
\hline miR-765 & Unknown & - & Coronary artery disease & [78] & eNOS & {$[76,77]$} \\
\hline
\end{tabular}

NO bioavailability, inhibiting vascular growth factors and reducing senescence modulators to maintain the endothelial homeostasis. During pathophysiological conditions, such as obesity, SIRT1 expression is altered in the vasculature leading to endothelial dysfunction [9295]. Our recent data have demonstrated that SIRT1 is reduced in ECs from obese mice, while protecting SIRT1 preserves endothelial function by protecting caveolin-1 expression and reducing ER stress [91] (Fig. 4).
Our group has further demonstrated that miR-204 is an important factor that regulates vascular SIRT1 [91]. During obesity, miR-204 is highly expressed in ECs, leading to decreased levels of SIRT1 and endothelial dysfunction. Inhibition of miR-204 rescues impaired endothelial-dependent vasorelaxation and vascular expression of SIRT1 [91]. These findings indicate that SIRT-1 is a direct target of miR-204 and manipulating vascular miR-204 expression during obesity can

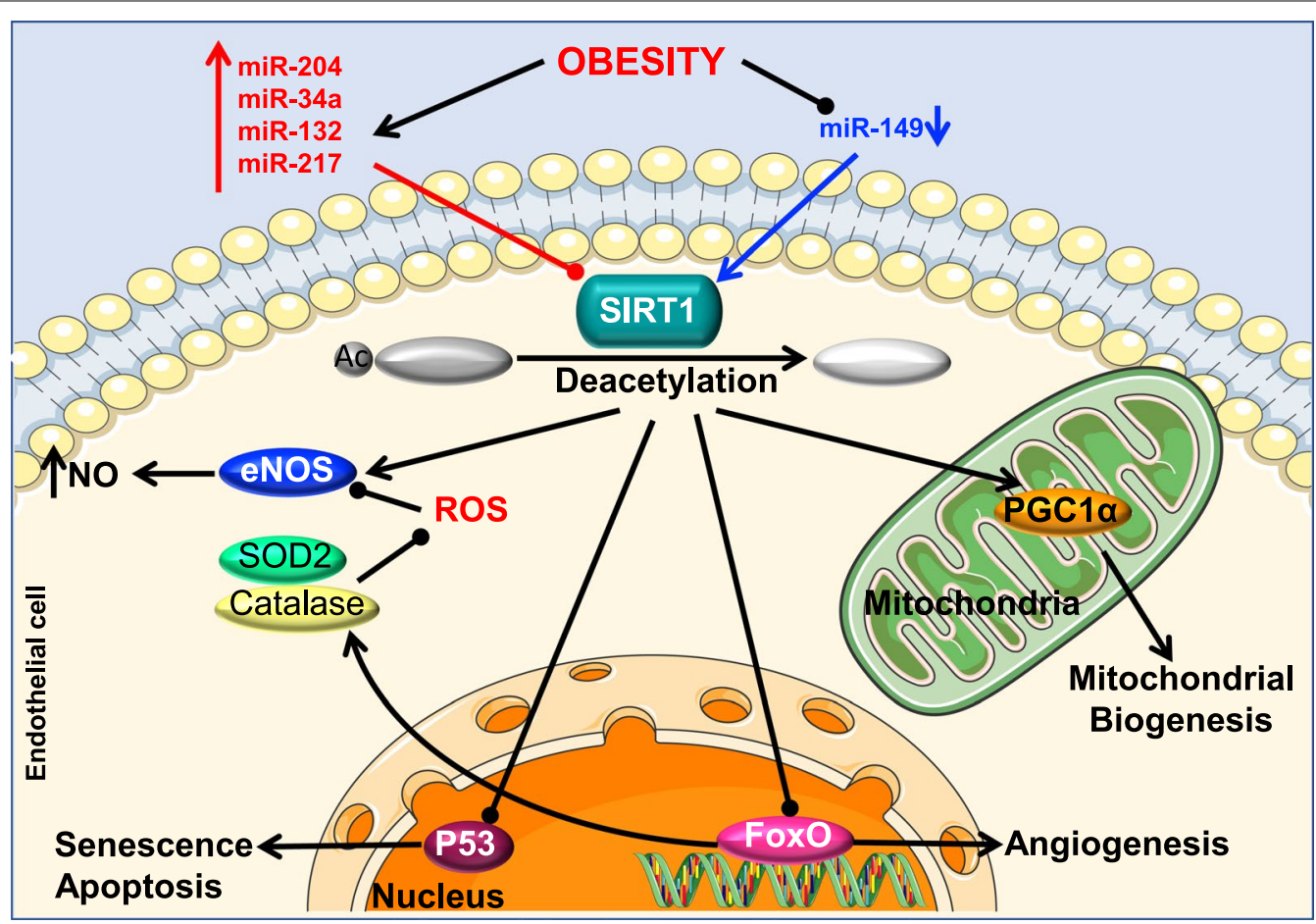

Fig. 4 Obesity, SIRT1, miRNAs and endothelial function. SIRT1 directly deacetylates eNOS, PGC-1 a, p53, and FoxO1 leading to enhanced NO bioavailability and mitochondrial biogenesis as well as, decreased senescence, angiogenesis, apoptosis, and oxidative stress. All of these effects allow for the maintenance of endothelial homeostasis. Levels of miRNAs that directly target SIRT1 and thereby modulate endothelial function can be either increased (miR-204, miR-34a, miR-132, miR-217 and miR-200c) or decreased (miR-149) in obesity. SIRT1: Sirtuin 1; eNOS: endothelial Nitric Oxide Synthase; NO: Nitric Oxide; ROS: Reactive oxygen species; SOD2: Superoxide dismutase; P53: Tumor protein; FoxO: Forkhead box; PGC-1 a: Peroxisome proliferator-activated receptor gamma coactivator 1-alpha 
potentially be a great therapeutic target against obesityinduced endothelial dysfunction.

Obesity is also known to increase endothelial senescence and as a consequence, leads to endothelial dysfunction $[96,97]$. Several miRNAs have been shown to be involved in endothelial senescence, including miR217 and miR-34a $[98,99]$. These two miRNAs share a similar function as negative regulators of SIRT1 [98, 100]. Other studies have shown that overexpression of miR-217 and miR-34a in ECs from young individuals decreased SIRT1 expression and remarkably induced premature cell senescence $[98,99]$. Interestingly, these two miRNAs are increased during obesity $[100,101]$. From these findings, one could speculate that during obesity, these two upregulated miRNAs could influence the endothelial function through decreasing SIRT1 and inducing premature senescence pathways. Thus, further investigations of this pathway constitute a promising therapeutic strategy.

In addition, other studies have established miR-149 as an important player in preventing endothelial dysfunction [102]. MiR-149 stimulates the activity of SIRT1induced peroxisome proliferator-activated receptor $\gamma$ coactivator 1 alpha $(\mathrm{PGC} 1 \alpha)$ and mitochondrial biogenesis [103]. Upregulation of $\mathrm{PGC}-1 \alpha$ can prevent the development of, and even encourage regression of, atherosclerotic lesions during obesity [104]. HFD and obesity have been shown to significantly reduce the expression of miR-149, thereby lowering SIRT1 activity $[103,105]$. These findings suggest that, by restoring SIRT1, vascular miR-149 overexpression may exert protective effects on obesity-induced endothelial damage.

Similarly, miR-132 has been described as a direct regulator of SIRT1 [106]. This miRNA has been shown to be increased during obesity and to induce inflammation in ECs via reduction of SIRT1 [106-108]. Inflammation is tightly associated with vascular endothelial dysfunction in obese subjects [109]. Thus, regulating miR-132 level during obesity could have a beneficial effect on the endothelial function. All data are summarized in Table 2.

\section{Oxidative stress and miRNAs}

Protein oxidation and ROS (free radicals) play a crucial role in maintaining normal cell physiology [110]. The mitochondria are considered as the major source of ROS in most mammalian cells [111]. More specifically, the mitochondrial respiratory chain complexes I and III, located in the inner membrane of the mitochondria, generate the majority of superoxide anions $\left(\mathrm{O}_{2}\right)$ in the cell [111-114]. Nicotinamide-adenine dinucleotide phosphate (NADPH) oxidase, a cytoplasmic enzyme, is also known to contribute to ROS production, especially in the vasculature [115]. Under physiologic conditions and because of their high reactivity with other intracellular components, ROS generation is highly regulated by antioxidant defense mechanisms that scavenge the detrimental actions of ROS [114]. The antioxidant defense systems include superoxide dismutases (SODs), glutathione peroxidase (GSHPx), catalases (CATs), and peroxiredoxins (PRDXs) [116]. For example, SODs induce the dismutation of $\mathrm{O}_{2}$ to form $\mathrm{H}_{2} \mathrm{O}_{2}[116,117]$. At high proportions, $\mathrm{H}_{2} \mathrm{O}_{2}$ possesses toxic properties, but its effects are counteracted by GSHPx, CATs, and/or PRDXs [118]. Under pathophysiological conditions, an imbalance between the antioxidant system and the pro-oxidant species takes place and induces oxidative stress [119]. Studies have shown that oxidative stress by itself plays an important role in the pathogenesis of endothelial dysfunction during obesity [49]. Because of their dual roles in vascular dysfunction and obesity, the following section will discuss the potential crosstalk between ROS and miRNAs in the context of obesity-induced endothelial dysfunction (Fig. 5).

MiRNAs are potent regulators of redox homeostasis through antioxidant enzyme gene modulation [120, 121]. Mitochondrial respiratory chain complex I function depends on the usage of iron/sulfur cluster assembly enzymes (ISCU) as transient electron carriers [122, 123]. Reduction in ISCU blocks the electrons from exiting complex I, causing electron leakage and increased levels of ROS [122]. Interestingly, miR-210 is known to impair mitochondrial respiratory activity by directly targeting ISCU 1 and 2 isoforms, which then leads to superoxide

Table 2 MiRNA regulation during obesity, their function in the cardiovascular system and their potential targets in endothelial cells (SIRT1)

\begin{tabular}{|c|c|c|c|c|c|c|}
\hline miRNA & $\begin{array}{l}\text { Up/downregulation } \\
\text { (obesity) }\end{array}$ & Refs. & Function & Refs. & Target & Refs. \\
\hline miR-204 & Up & {$[91]$} & EC dysfunction & [91] & SIRT1 & {$[91]$} \\
\hline miR-217 & Up & [101] & Premature cell senescence & [98] & SIRT1 & {$[98]$} \\
\hline miR-34a & Up & {$[100]$} & Premature cell senescence & [99] & SIRT1 & [100] \\
\hline miR-149 & Down & {$[103,105]$} & Regression of atherosclerotic lesions & {$[104]$} & SIRT1 & [103] \\
\hline miR-132 & Up & [106-108] & Macrophage infiltration in ECs & [106-108] & SIRT1 & [106] \\
\hline
\end{tabular}




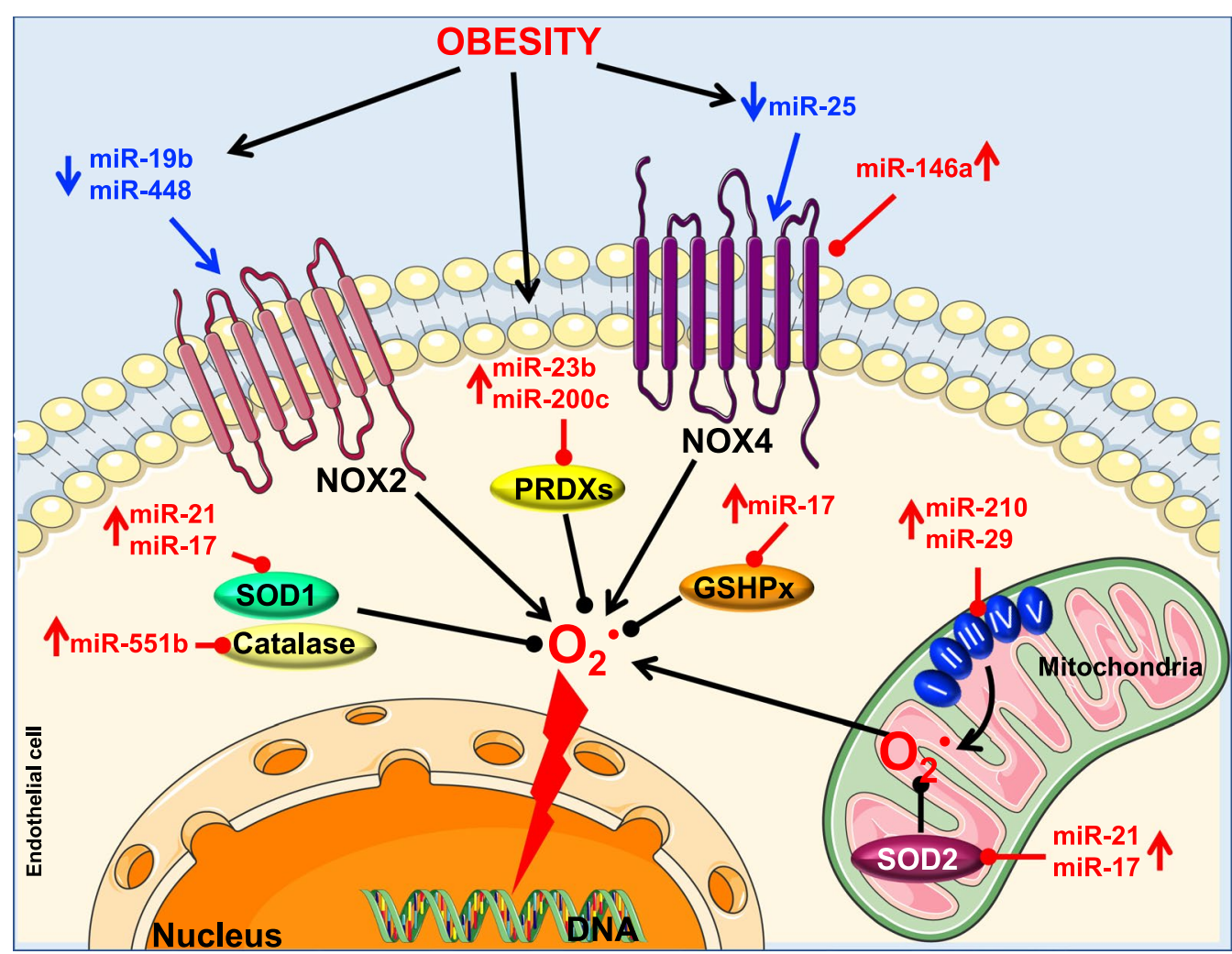

Fig. 5 Obesity, oxidative stress, miRNAs and endothelial function. Superoxide anions $\left(\mathrm{O}_{2}\right)$ are mainly produced by NOX2, NOX4 and mitochondria through electron transport chain complex I and III. Under physiological conditions, $\mathrm{O}_{2}$ are highly regulated by antioxidant mechanism through SOD that detoxifies $\mathrm{O}_{2}$ to hydrogen peroxide $\left(\mathrm{H}_{2} \mathrm{O}_{2}\right)$, which is then converted to water $\left(\mathrm{H}_{2} \mathrm{O}\right)$ by catalase or glutathione peroxidase $(\mathrm{GSHPx})$ and peroxiredoxins (PRDXs). Obesity interferes with the normal workings of this system. By decreasing miR-448-3p and miR-19b, it increases NOX2 levels. At the same time, it decreases miR-25 while increasing miR-146a, which can cause up or downregulation of NOX4 levels respectively (NOX4 has dual effect). Additionally, obesity increases the levels of miR-210 and miR-29, both of which affect the mitochondrial respiratory chain. Moreover, obesity modulates the levels of miRNAs that regulate the antioxidant system (e.g. miR-21 and miR-17, both of which target SOD, with miR-17 additionally targeting GSHPx; and miR-23b and miR-200c, both of which target PRDXs). Altogether, the modulation of miRNA levels during obesity leads to excessive production of $\mathrm{O}_{2}$ and consequently endothelial dysfunction. SOD: Superoxide dismutase; GSHPx: glutathione peroxidase; PRDXs: peroxiredoxins; NOX2: catalytic, membrane-bound subunit of NADPH oxidase; NOX4: NADPH oxidase homolog

anion production [124]. Additionally, recent evidence has shown that miR-210 induces ECs apoptosis during atherosclerosis [125] and is associated with cardiovascular diseases [126-129]. Although these findings have established a strong correlation between miR-210 and mitochondrial ROS production during cardiovascular diseases, further investigation is needed to show its role in obesity-induced endothelial dysfunction.

As mentioned above, miRNAs can increase cellular ROS generation/levels by directly targeting antioxidant genes [120, 129]. For instance, miR-21, expressed in ECs [52] and reported to be increased in human subjects with obesity [130, 131], directly alters SOD expression in order to promote ROS production [132, 133]. Similarly, miR-551b has been shown to enhance ROS accumulation by directly inhibiting the gene expression of either CAT [134] or FOXO3a, the transcription factor that induces
SOD and CAT transcription [135]. Both SOD and CAT play a crucial role in maintaining endothelial function [136-138]. Interestingly, increased levels of miR-551b lead to endothelial dysfunction in patients with coronary artery disease [139]. Higher expression levels of miR$551 \mathrm{~b}$ have been also reported in obesity [140]. Taken together, these findings suggest that inhibiting both miR21 and miR-551b could prevent oxidative stress and consequently improve endothelial function in patients with obesity.

In diabetes, miR-200c is implicated in endothelial dysfunction, and its inhibition has been demonstrated to rescue endothelium-dependent vasodilation [141]. In subjects with obesity, miR-200c was found to circulate at higher levels $[142,143]$. In addition, miR-200c negatively regulates redox proteins such as PRDX2, leading to accumulation of ROS [144] and consequently to senescence 
and apoptosis in ECs [145]. Taken all together, these findings suggest that miR-200c plays a role in the pathophysiological effects of obesity on endothelial function via oxidative stress. Additionally, miR-23b, which is expressed in ECs and plays an important role in vascular disorders $[52,146]$, has been shown to downregulate the antioxidant PRDX3 [147]. Furthermore, patients with cardiovascular disease risk display increased circulating levels of miR-23b [148]. These findings lead us to believe that miR-23b inhibition during obesity may induce beneficial effects on endothelial function.

Major mitochondrial antioxidant enzymes, including SOD and Gpx2, have been shown to be inhibited by miR-17 [149]. Furthermore, studies unveiled that miR17, upregulated through inflammatory processes [150], is involved in the pathogenesis of endothelial dysfunction in the context of obesity and diabetes $[151,152]$. Although miR-17 expression has been correlated to obesity-induced endothelial dysfunction, further pharmacological studies, in particular inhibitory experiments, are required to confirm its mechanisms of action.

MiR-29 isoforms have been described to affect the mitochondrial function leading to ROS production [153]. These isoforms are upregulated in animal models of metabolic disorder [154], induced endothelial cell dysfunction [155], and cellular senescence [156]. Because both endothelial dysfunction and senescence are present during obesity [97], targeting miR-29 in the vascular endothelium during obesity may have a beneficial effect on endothelial function.

NADPH oxidase (NOX) 2 and 4 are isoforms of NADPH oxidase that are highly expressed in the vasculature [115]. NOXs are known to be upregulated during obesity. This upregulation leads to excessive ROS production and consequently to endothelial dysfunction [157]. Unlike NOX4, whose activity is induced constitutively [158], the inducible NOX2 requires the intervention of p47phox and p67phox as organizer and activator, respectively [159]. NOX2-derived ROS plays a major role in models of HFD-induced endothelial dysfunction [160]. In terms of relevant miR, miR-448 plays an important role in the regulation of NOX2-derived ROS production in the heart. In fact, silencing miR-448 substantially increases NOX2-derived ROS production and facilitates the development of cardiomyopathy [161]. In patients with obesity, miR-448 is expressed at low levels $[162,163]$. While there are no direct studies of this miR in ECs, we anticipate that in a model of obesity-induced endothelial dysfunction, lower levels of miR-448 will induce NOX2-derived ROS production, which will then lead to impaired endothelial function.

In vitro studies have shown that miR-19b directly inhibits p47phox-induced ROS production [164].
Moreover, miR-19b has been reported to play a key role in the attenuation of inflammation-induced EC apoptosis [165]. In addition, decreased circulating levels of miR19b were observed in HFD-induced obese mice [166]. These findings imply that reduction of miR-19b in obesity may lead to increase in p47phox-induced ROS production and endothelial dysfunction.

NOX4-derived ROS production has been implicated in endothelial dysfunction and inflammation during obesity $[167,168]$. Evidence has shown that miR-25 is expressed in ECs [169]. Interestingly, in vitro inhibition of miR-25 increases NOX4 expression and ROS levels, while its overexpression prevents NOX4-derived ROS production [170]. Rats under high cholesterol diet display lower miR25 expression, which is associated with increased NOX4 expression levels [170]. While the relevance of these findings in the vasculature requires functional verification, this study indicates that miR-25 may directly target NOX4 to induce ROS production in ECs during obesity.

Although several papers have reported the detrimental effects of NOX4-derived ROS production in the vascular system, other studies have demonstrated the beneficial effects of NOX4 in the vessel bed. In fact, NOX4 has been reported to induce eNOS upregulation and to inhibit vascular inflammation during atherosclerosis [171, 172]. In this context, miR-146a has been shown to directly inhibit NOX4 expression, thereby causing endothelial inflammation [173]. Both animal models and patients with obesity express higher levels of miR-146a in adipose tissue [174]. Taken together, these studies point toward the importance of miR-146a in directly regulating the beneficial effects of NOX4 on the endothelium during obesity.

In summary, this section points toward the rising importance of studying the role of redox-sensitive microRNAs in order to identify more effective biomarkers and develop better therapeutic targets for the plethora of oxidative stress-related diseases, especially in the context of obesity-induced endothelial dysfunction. All data are summarized in Table 3.

\section{Autophagy and miRNAs}

Autophagy is an evolutionarily conserved mechanism that maintains cellular and nutrient homeostasis by degrading misfolded proteins and damaged organelles [175]. Dysregulation of autophagy is a major contributor to the pathogenesis of several chronic diseases including obesity-induced cardiovascular dysfunction [176, 177]. A number of recent studies have identified miRNAs that target autophagy-related proteins and that influence the autophagy flux. In this section, we will uncover the potential role of these miRNAs in the regulation of endothelial function in the context of obesity (Fig. 6). 
Table 3 MiRNA regulation during obesity, their function in the cardiovascular system and their potential targets in the redox system

\begin{tabular}{lllllll}
\hline miRNA & $\begin{array}{l}\text { Up/ } \\
\text { downregulation } \\
\text { (obesity) }\end{array}$ & Refs. & Function & Refs. & Target & Refs. \\
\hline miR-210 & Unknown & - & EC apoptosis and atherosclerosis & {$[125]$} & ISCU 1,2 & {$[124]$} \\
miR-21 & Up & {$[130,131]$} & Promotes ROS production & {$[132,133]$} & SOD & {$[132,133]$} \\
miR-551b & Up & {$[[140]$} & Enhances ROS accumulation & {$[134,135]$} & CAT, SOD & {$[134,135]$} \\
miR-200c & Up & {$[142,143]$} & EC apoptosis, ROS accumulation and senescence & {$[144,145]$} & PRDX2 & {$[144]$} \\
miR-17 & Up & {$[151,152]$} & EC dysfunction & {$[151,152]$} & SOD, Gpx2 & {$[149]$} \\
miR-23b & Up & {$[148]$} & EC dysfunction & {$[52,146]$} & PRDX3 & {$[147]$} \\
miR-29 & Up & {$[154]$} & EC dysfunction, Cellular senescence & {$[155,156]$} & ROS & {$[153]$} \\
miR-448 & Down & {$[162,163]$} & Attenuation of NOX2 induced-ROS accumulation & {$[161]$} & NOX2 & {$[161]$} \\
miR-19b & Down & {$[166]$} & Attenuation of inflammation-induced EC apoptosis & {$[165]$} & P47phox & {$[164]$} \\
miR-25 & Down & {$[170]$} & Prevent ROS production & {$[170]$} & NOX4 & {$[170]$} \\
miR-146a & Up & {$[174]$} & EC inflammation & {$[173]$} & NOX4 & {$[173]$} \\
\hline
\end{tabular}

There are three forms of autophagy: macroautophagy, microautophagy, and chaperone-mediated autophagy [175]. In this review, we will focus only on macroautophagy, which is the most important and well-studied in regard to obesity and endothelial function. Macroautophagy is characterized by three main steps: initiation and vesicle nucleation, elongation and autophagosome formation, and fusion of the autophagosome with the lysosome and degradation. The whole process is called autophagy flux. The initiation phase is orchestrated by unc-51-like kinase 1 (ULK1) complex which consists of ULK1 itself, autophagy-related protein (ATG) 13, focal adhesion kinase family interacting protein of $200 \mathrm{kDa}$ (FIP200), and ATG101. The ULK1 complex drives the formation of the phagophore, the initial autophagosomal precursor membrane structure, through direct activation of vacuolar protein sorting 34 (VPS34) complex. The VPS3A complex consists of the class III phosphatidylinositol 3-kinase (PIK3C3)/VPS34, BECLIN-1, VPS15 and ATG14-like. ULK1 activity is controlled by two nutrient-regulated protein kinases, $5^{\prime}$ adenosine monophosphate-activated protein kinase (AMPK) and mammalian target of rapamycin (mTOR) complex 1 (mTORC1). While AMPK upregulates autophagy in response to energy depletion by directly activating ULK1, mTORC1 keeps autophagy under control through direct inactivation of ULK1.

\section{MiRNAs in the regulation of autophagy initiation}

As important regulators of autophagy, mTOR and AMPK are regulated by miRNAs.

miR-155, miR-199a and miR-101 directly target mTOR in different cell types [178-182]. Interestingly, all three of these miRNAs have been found at increased levels during obesity and other metabolic diseases, and have been proven to have a detrimental effect on vascular and endothelial function [65, 183-188]. The relationship between mTOR and endothelial dysfunction is well documented [189]. In fact, a study has shown that chronic inhibition of the mTOR pathway in human aortic rings leads to a reduction in endothelium-mediated vasodilation [190]. Moreover, obesity has been proven to reduce the activity of the mTOR pathway and lead to endothelial dysfunction in vasculature of animal models of obesity [191]. The reactivation of the mTOR pathway in these models improves microvascular endothelium-dependent vasodilation [191]. Altogether, these data provide a solid link between the miRNAs, obesity and endothelial dysfunction through mTOR regulation.

AMPK is also targeted by miRNAs, including miR$148 \mathrm{~b}$ and miR-451 [192, 193]. miR-148b is stimulated during obesity [194] and plays an important role in hyperglycemia-induced endothelial dysfunction [155]. miR-451 overexpression induces AMPK inhibition, which then leads to mTORC1 over-activation [195]. In addition, microarray analysis of the heart tissue of mice on HFD has shown that, by reducing AMPK, miR-451 plays a role in the development of cardiac hypertrophy [193]. While this study uncovered the link between miR451 and AMPK during obesity, miR-451's role in the vascular endothelium and its contribution to the endothelial dysfunction in the context of obesity remains to be examined. The link between AMPK and endothelial dysfunction has been studied in HFD-induced animal models of obesity [196]. In this study conducted by Ma et al., HFD led to aortic AMPK downregulation and endothelial dysfunction [196]. Other studies have also shown that pharmacological activation of AMPK leads to markedly 


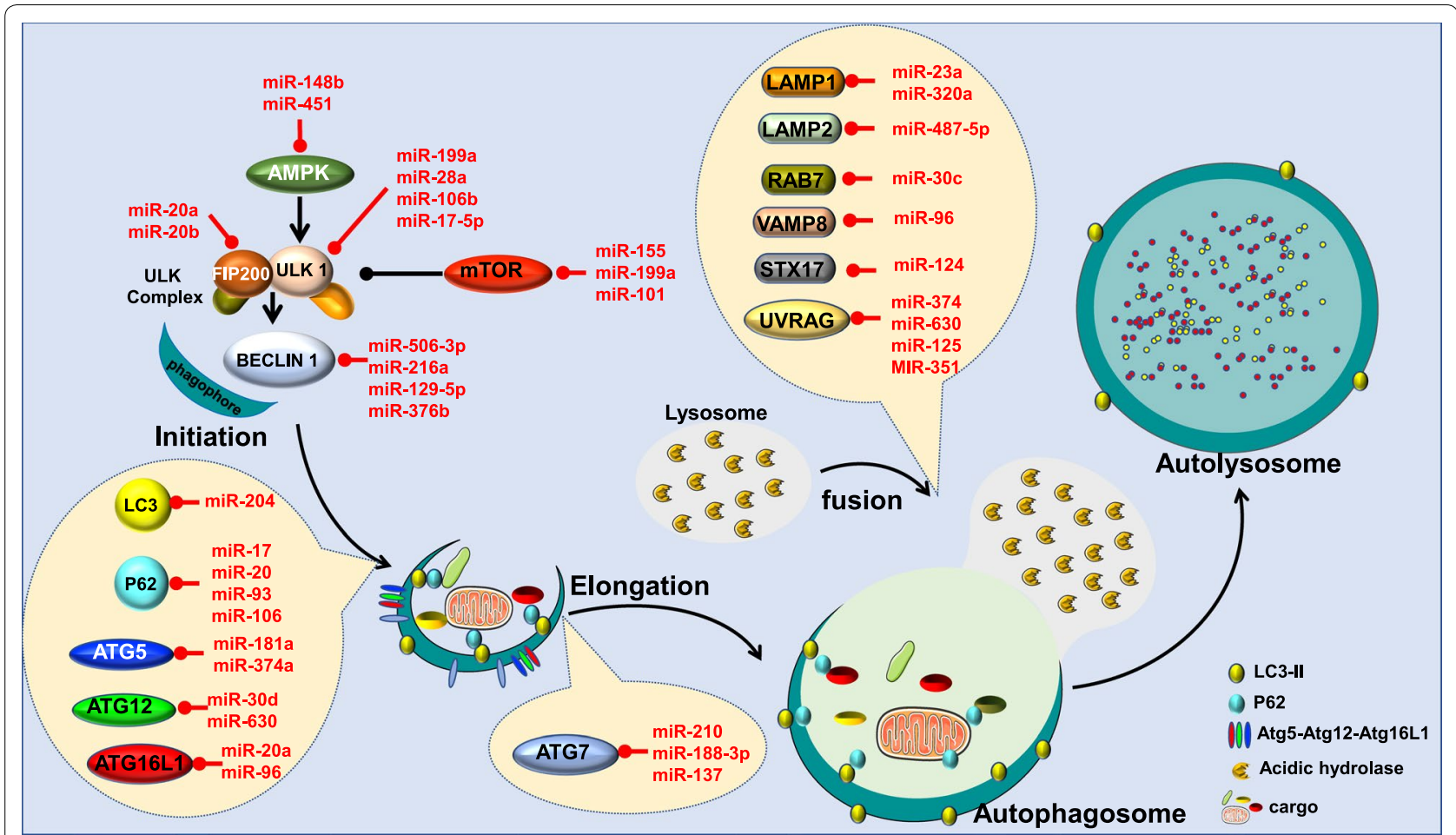

Fig. 6 Obesity, autophagy flux, miRNAs and endothelial function. Autophagy flux consists of a series of steps including initiation, elongation, fusion of the autophagosome with the lysosome and degradation. Autophagy induction is controlled by mTOR and AMPK, which tightly regulate the ULK complex: ULK1, ATG13 and FIP200. By modulating miRNA levels, obesity regulates autophagy induction. During obesity, increased levels of miR-155, miR-199a-5b and miR-101 are expressed and all directly target mTOR. miR-148b and miR-451, also increased during obesity, target AMPK. miR-199a, miR-28a, miR-106b and miR-17-5p target ULK1, while miR-20a and miR-20b target FIP200. Beclin1, which also plays an important role in autophagy initiation, is targeted by miR-506-3p, miR-216a, miR-129-5p and miR-376b. These four miRNAs are known to be increased during obesity. Autophagosome elongation involves ATG5, ATG7, ATG 12, ATG-16L1, LC3 and p62. ATG 5 can be suppressed by miR-181a and miR-374a; ATG7 by miR-210, miR-188-3p and miR-137; ATG 12 by miR-30d and miR-630 and ATG 16-L1 by miR-20a and miR-96. All these miRNAs are increased during obesity. LC3-II is post-transcriptionally controlled by miR-204, which is known to be induced during obesity. P62 is controlled by miR-17, miR-20, miR-93 and miR-106, which are all also increased during obesity. The fusion and degradation step is controlled by UVRAG, LAMP-1/2, RAB7, VAMP8 and STX17. All of these membrane fusion factors are tightly regulated by miRNAs. UVRAG is suppressed by miR-374, miR-630, miR-125, and miR-351; Lamp1 is inhibited by miR-23a and miR-320a, while LAMP2 is inhibited by miR-487-5p; Rab7, VAMP8 and STX17 are regulated by miR-30c, miR-96, and miR-124, respectively. All of these miRNAS are induced by obesity. In summary, the modulation that takes place in miRNA levels during obesity leads to autophagy flux disruption-induced endothelial dysfunction. ULK1: unc-51-like kinase 1; FIP200: focal adhesion kinase family interacting protein of 200 kDa; mTOR: mammalian target of rapamycin; ATG: autophagy-related protein; LC3: Microtubule-associated protein 1A/1B-light chain 3; p62: sequestrome 1; UVRAG: UV resistance-associated gene; VAMP8: vesicle-associated membrane protein; STX17: Syntaxin; LAMP: Lysosome-associated membrane proteins; Rab7: Ras-related protein

improved endothelial function [197]. Therefore, manipulating miRNAs that target AMPK during obesity could be a relevant therapeutic tool to restore endothelial function.

A recent study has uncovered the protective role of ULK1 in obesity-induced cardiac damage [198]. Obesity decreases ULK1 and leads to lipotoxicity in cardiomyocytes and consequently heart dysfunction [198]. Despite the preventive role of ULK1 in the context of obesity-induced damage, the relation between ULK1 and endothelial dysfunction in obesity has not been studied. However, there is evidence that miR-199a inhibits ULK1 complex, which then causes vascular endothelial impairment and consequently hypertension [185]. Interestingly, miR-199a is increased during obesity [182, 188], suggesting that manipulating this miRNA could restore endothelial function during obesity. Other studies have focused on miR-20a, miR-106b and miR-17-5p, three miRNAs proven to affect ULK1 complex [199-202]. Compared to healthy individuals, subjects with obesity display increased levels of miR-20a [143] which has been shown to regulate EC migration and angiogenesis, two important processes for endothelial function [203]. Similarly, miR-106b has been found to be highly expressed during metabolic disorders, in which it induces mitochondrial dysfunction [204]; its knockdown counterpart 
decreases endothelial proliferation and prevents atherosclerosis [205]. Likewise, miR-17-5p expression differs significantly between patients with and without obesity [206]. Downregulation of this miRNA improves cardiac function after a myocardial infarction through attenuation of EC apoptosis [207]. Altogether, these studies point toward the importance of the ULK1 in the cardiovascular system and more specifically endothelial function. Therefore, monitoring the miRNAs that regulate the ULK1 complex during obesity would have positive effects on the vascular bed.

Among the other players of autophagy initiation, miR$20 \mathrm{a}$ and miR-20b have been shown to negatively regulate autophagy via targeting FIP200 [208]. Both miR-20a and miR-20b have been found at higher levels in patients with obesity $[143,209]$ and have been demonstrated to promote senescence in human microvascular ECs [210, 211]. Regulating these miRNAs, which regulate FIP200 during obesity, could have a beneficial effect on the endothelial function.

The reduction of Beclin 1 is associated with vascular ECs injury in hypertensive patients. In this study, Zhong et al. showed that downregulating Beclin 1 expression in hypertensive patients via miR-506-3p upregulation, aggravates injury in vascular ECs [212]. Although the association between hypertension and obesity has been extensively studied and established [213-215], no study has linked miR-506-3p to obesity. Establishing this connection could constitute an important advancement in obesity-induced vascular dysfunction therapy. Another player in the regulation of autophagy initiation is
miR-216a. Mir-216a controls ox-LDL induced autophagy in ECs by regulating intracellular levels of Beclin1 and may have a therapeutic role in the pathogenesis of cardiovascular disorders and atherosclerosis [216]. MiR-129-5p, a known tumor suppressor [217], is induced during HFD and alters endothelial autophagy by directly binding to Beclin 1 [218]. Similarly, miR-376b, which is also found at high levels in subjects with obesity [219], targets Beclin 1 and induce autophagy impairment in different cell types [220]. Interestingly, a study has uncovered the role of miR-376b in metabolic disease-induced EC dysfunction [155], suggesting that targeting this miRNA is a promising approach to regulate autophagy and endothelial function during obesity. While the previous studies help establish a strong relationship between miRNAs and Beclin 1 in obesity, their relationship to obesity-induced endothelial dysfunction requires further exploration. All data are summarized in Table 4.

\section{MiRNAs in the regulation of autophagy elongation}

After vesicle nucleation, elongation of the phagophore's membrane constitutes a fundamental step in the formation of a complete and functional autophagosome. This process involves ATG proteins (i.e. ATG 3, 4, 5, 7, 8, 10, 12 , and $16 \mathrm{~L}$ ) and the microtubule-associated protein 1 light chain (LC3) [221]. The ATG system is required for the LC3 to conjugate to phosphotidylethanolamine (PE) phospholipids and to form LC3 II. LC3 II is important for the expansion of the membrane, where it plays a crucial role in cargo recognition via its interaction to

\begin{tabular}{|c|c|c|c|c|c|c|}
\hline miRNA & $\begin{array}{l}\text { Up/ } \\
\text { downregulation } \\
\text { (Obesity) }\end{array}$ & Refs. & Function & Refs. & Target & Refs. \\
\hline miR-155 & Up & [65] & EC dysfunction & [183] & mTOR & {$[178,181]$} \\
\hline miR-199a & Up & {$[184,188]$} & EC dysfunction & [185] & mTOR, ULK1 & {$[178,180,182,185]$} \\
\hline miR-101 & Up & {$[186,188]$} & EC dysfunction & [187] & mTOR & {$[178,179]$} \\
\hline miR-451 & Up & [193] & Cardiac hypertrophy & [193] & AMPK & {$[193,195]$} \\
\hline miR-148b & Up & [194] & Hyperglycemia-induced EC dysfunction & [155] & AMPK & [192] \\
\hline miR-20a & Up & [143] & $\begin{array}{l}\text { Regulates EC migration, angiogenesis and } \\
\text { senescence }\end{array}$ & {$[203,211]$} & ULK1, FIP200 & {$[199,208]$} \\
\hline miR-20b & Up & [209] & Promotes EC senescence & {$[210,211]$} & FIP200 & {$[208]$} \\
\hline miR-106b & Up & [204] & EC proliferation and atherosclerosis & {$[205]$} & ULK1 & {$[199,201]$} \\
\hline miR-17-5p & Up & {$[206]$} & ECs apoptosis and cardiac dysfunction & [207] & ULK1 & {$[202]$} \\
\hline miR-506-3p & Unknown & - & Aggravates injury in vascular EC & [212] & Beclin 1 & {$[[212]$} \\
\hline miR-216a & Unknown & - & Controls ox-LDL induced autophagy & [216] & Beclin 1 & {$[216]$} \\
\hline miR-129-5p & Up & [218] & Alters EC autophagy & {$[218]$} & Beclin 1 & [218] \\
\hline miR-376b & Up & [219] & Autophagy impairment, EC dysfunction & {$[155,220]$} & Beclin 1 & {$[220]$} \\
\hline
\end{tabular}


sequestrome 1, also known as the ubiquitin-binding protein p62 [221].

Similar to the components of autophagy initiation, ATG proteins are regulated by multiple miRNAs. Beyond its major role in the autophagy elongation, ATG5 holds a pivotal part in the process cell survival [222]. As such, a variety of different miRNAs take part in its regulation. For instance, miR-181a is an active inhibitor of ATG5 [223]. miR-181a is upregulated in human atherosclerosis plaques and involved in oxidative stress-induced EC dysfunction through by directly targeting autophagy machinery [224]. Moreover, it is found to be associated with the pathogenesis of obesity, [225] and its downregulation has the potential to reverse these effects [226]. In a similar manner, miR-374a has been suggested to regulate ATG5 [227]. MiR-374a has been linked to metabolic disorder during obesity [228] and can promote heart dysfunction by negatively regulating vascular endothelial growth factor (VEGF) receptor-1 signaling [229].

MiR-30d, shown to directly target and suppress ATG12 [230], is found at increased levels in subjects with obesity [58]. Although its implication in vascular function has not been assessed yet, existing data leads us to assume that downregulation of miR-30d in models with obesity, will induce a beneficial effect on endothelial function. Likewise, miR-630 suppresses autophagy by targeting ATG12 [230]. Interestingly, miRNA-630 has been designated as a putative key mediator of vascular function and cardiovascular disease risk in patients with obesity [231].

Similar to ATG12, ATG7 is also implicated in the development of atherosclerosis [232]. This protein is shown to be negatively targeted by miR-210, miR-188-3p and miR137 [233-235]. MiR-210 is involved in ECs apoptosis during atherosclerosis [125] and is associated with cardiovascular diseases [126-129]. Comparably, miR-188-3p upregulation results in the induction of atherosclerosis [236], a disease that has been widely associated with obesity [61]. In regard to miR-137, which is also involved in obesity [237], studies have established that high glucose levels induce dysfunction of human ECs by upregulating miR-137 [238]. This suggests the involvement of miR137 in the pathogenesis of obesity-induced endothelial dysfunction.

ATG16L1 has been shown to be another target of miRNAs such as miR-20a [239] and miR-96 [240]. Interestingly, both of these miRNAs are found to be upregulated during obesity [17, 241], and studies have demonstrated their implication in the functionality of the vascular system [203, 242]. This indicates their potential involvement in the pathogenesis of obesity-induced vascular damage.

As important markers of autophagy process, LC3 and p62 are also regulated by miRNAs. To be specific, LC3 is targeted by miR-204 [243]. Our group has previously shown that obesity is associated with increased levels of vascular miR-204, which lead to endothelial dysfunction [44]. From our findings, we believe that further exploring the mechanisms underlying obesity-induced endothelial damage with respect to miR-204 and autophagy could represent a novel strategy for obesity treatment and prevention. On the other hand, p62 has been shown to be targeted by the miR-17/20/93/106 family of miRNAs [244]. Most of these family members are involved in endothelial dysfunction. In fact, when induced by VEGF, miR-17 triggers ECs to switch to an angiogenic phenotype which has been linked to atherosclerosis and obesity [245]. As discussed above, miR-20a, miR-20b and miR106 are all involved in the pathogenesis of obesity and endothelial dysfunction [17, 143, 192, 203, 205, 209-211]. Finally, miR-93, which plays an important role in adipogenesis [246], has been shown to regulate endothelial glycolysis and proliferation $[247,248]$ and to contribute to coronary atherosclerosis pathogenesis [239]. All data are summarized in Table 5.

\section{MiRNAs in autophagy fusion and degradation regulation}

Once the autophagosome has formed and matured, it fuses with a lysosome to form an autolysosome. The inner membrane of the former autophagosome and the engulfed cargo are then degraded by acid hydrolases [249]. Autophagosome-lysosome fusion machinery includes UV resistance-associated gene (UVRAG), Soluble $\mathrm{N}$-ethylmaleimide sensitive factor (NSF) Attachment Protein Receptor (SNARE) complexes, vesicle-associated membrane protein (VAMP) 8, Syntaxin (STX) 17, Lysosome-associated membrane proteins (LAMP) $1 / 2$ and RAB 7 [250]. Although poorly studied, a number of miRNAs have been reported to regulate the fusion of autophagosome and lysosome [251]. Studies have established that lysosomal dysfunction occurs and is involved in the pathology of obesity [252]. In addition, lysosomal dysfunction has been proven to induce ECs apoptosis and senescence [253]. Therefore, regulating the late phase of autophagy during obesity could bring new insight into therapeutic approaches for vascular diseases.

UVRAG, an important player in the fusion process, is targeted by miR-374, miR-630, miR-125 and miR-351 $[227,254]$. The characteristics of both miR-374 and miR630 were discussed in the previous sections. miR-125 is implicated in the process of atherosclerosis development [255] and ECs senescence [256]. miR-351 is upregulated in the serum and ECs of atherosclerotic animal models and has been shown to attenuate ECs survival [257].

Lamp1, a primary marker of the lysosome fusion process, is a target of both miR-23a [258] and miR-320a [259]. MiR-23a plays an important role in the development of atherosclerotic plaques [260] and is a potential 
Table 5 MiRNA regulation during obesity, their function in the cardiovascular system and their potential targets in autophagy elongation and nucleation machinery

\begin{tabular}{|c|c|c|c|c|c|c|}
\hline miRNA & $\begin{array}{l}\text { Up/ } \\
\text { downregulation } \\
\text { (Obesity) }\end{array}$ & Refs. & Function & Refs. & Target & Refs. \\
\hline miR-181a & Up & {$[225,226]$} & Oxidative stress-induced EC dysfunction and atherosclerosis & [224] & ATG5 & [223] \\
\hline miR-374a & Up & [228] & $\begin{array}{l}\text { Negatively regulates vascular endothelial growth factor recep- } \\
\text { tor-1 signaling }\end{array}$ & {$[229]$} & ATG5 & [227] \\
\hline miR-30d & Up & [58] & Unknown & - & ATG12 & [230] \\
\hline miR-630 & Up & [231] & Suppresses autophagy & [231] & ATG12 & [230] \\
\hline miR-210 & Up & {$[125]$} & EC apoptosis and atherosclerosis & [125] & ATG7 & [233] \\
\hline miR-188-3p & Unknown & - & Induction of atherosclerosis & [236] & ATG7 & [234] \\
\hline miR-137 & Up & [237] & EC dysfunction & [238] & ATG7 & [235] \\
\hline miR-20a & Up & [17] & EC dysfunction & [203] & ATG16L1 & [239] \\
\hline miR-96 & Up & [241] & EC dysfunction & [242] & ATG16L1 & [240] \\
\hline miR-204 & Up & [44] & EC dysfunction & {$[[44]$} & LC3 & [243] \\
\hline miR-17 & Up & [206] & Triggers a switch of EC to an angiogenic phenotype & {$[245]$} & P62 & [244] \\
\hline miR-93 & Up & [246] & Regulates EC glycolysis and proliferation & {$[239,247,248]$} & P62 & [244] \\
\hline miR-20a & Up & [17] & Regulates EC migration, angiogenesis and senescence & [203] & P62 & [244] \\
\hline miR-20b & Up & [209] & Promotes EC senescence & [210] & P62 & [244] \\
\hline miR-106 & Up & [204] & EC proliferation and atherosclerosis & {$[205]$} & P62 & [244] \\
\hline
\end{tabular}

marker for coronary artery disease [261]. miR-320a, on the other hand, has altered circulating levels in metabolic diseases [262] and is considered a key regulator of atherogenesis [263].

Lamp2 is suppressed by miR-487-5p, [264] which has been found at higher levels in subjects with obesity [140]. Although no direct evidence has shown the implication of this miRNA in the vasculature, because Lamp2 is so crucially involved vascular function and integrity [265], we believe that we may gain some important insights by exploring this mechanism in the context of obesityinduced endothelial dysfunction.

Implicated in atherosclerosis [266], miR-30c is an efficient positive regulator of Rab7 [267]. Interestingly, both HFD and obesity downregulate miR-30c expression $[268,269]$ exacerbating the inflammatory process and cardiomyopathy. Although no evidence indicates that these processes would take place in the vascular bed in the context of obesity, data have demonstrated that restoration of autophagy flux through Rab7 in ECs reverses endothelial damages [270].

Finally, along the same lines, miR-96 has been predicted to bind to VAMP8 [271], and miR-124 to STX17 [272]. Both miR-96 and miR-124 have been linked to metabolic disorders and EC impairment [241, 273-275].

In the above section, we have listed the miRNAs and dissected their regulatory roles in the autophagy flux pathway; however, the interplay between autophagy machinery and miRNAs is much more complex. DICER and the AGO2, enzymes that regulate miRNAs biogenesis [276], are direct targets of the autophagolysosomal degradation. This indicates that autophagy and miRNA interactions work both ways and controlling one way would lead to a disruption of other processes and alter other physiological cellular functions. Thus, it is important to consider every single pathway that each miRNA is involved in, before exerting any potential manipulations in the context of obesity-induced vascular events. All data are summarized in Table 6.

\section{Endoplasmic reticulum (ER) stress and miRNAs}

The endoplasmic reticulum (ER) is the most important subcellular membrane organelle. It plays a crucial role in protein synthesis and folding, as well as in the control of cellular calcium concentrations [277]. If the protein synthesis and folding process fails, proteins will accumulate inside the ER, automatically triggering a defense mechanism called unfolded protein response (UPR). UPR represses protein synthesis and increases ER chaperone content in a bid to restore normal ER function [278]. In mammalian cells, the UPR is activated by three specialized arms: protein kinase R-like ER kinase (PERK), inositol-requiring enzyme (IRE) 1 , and activating transcription factor (ATF) 6. Under normal conditions, $78 \mathrm{kDa}$-glucose-regulated protein/ immunoglobulin binding protein (GRP78/BIP), an ER chaperone, binds to and maintains the inactivity of IRE1 $\alpha$, PERK, and ATF-6. Under stressful conditions 


\begin{tabular}{|c|c|c|c|c|c|}
\hline miRNAs & $\begin{array}{l}\text { Up/downregulation } \\
\text { (Obesity) }\end{array}$ & Refs. & Function & Refs. & Target \\
\hline miR-374 & Up & [228] & $\begin{array}{l}\text { Deregulating vascular endothelial growth factor } \\
\text { receptor-1 signaling }\end{array}$ & [229] & UVRAG \\
\hline miR-630 & Up & {$[231]$} & Suppresses autophagy & {$[231]$} & UVRAG \\
\hline miR-125 & Up & {$[255,256]$} & EC senescence and atherosclerosis & {$[255,256]$} & UVRAG \\
\hline miR-351 & Up & [257] & Attenuate EC survival & {$[257]$} & UVRAG \\
\hline miR-23a & Up & {$[261]$} & Promotes atherosclerotic plaque formation & {$[260]$} & Lamp1 \\
\hline miR-320a & Up & [262] & Regulates atherogenesis & [263] & Lamp1 \\
\hline miR-487-5p & Up & [140] & Unknown & - & Lamp2 \\
\hline miR30c & Down & {$[268,269]$} & EC inflammation & {$[268,269]$} & Rab7 \\
\hline miR-96 & Up & {$[241]$} & EC impairment & {$[274]$} & VAMP8 \\
\hline miR-124 & Up & {$[273]$} & EC apoptosis & {$[275]$} & STX17 \\
\hline
\end{tabular}

such as misfolded protein accumulation (also known as ER stress), GRP78/BIP dissociates from IRE1 $\alpha$, PERK, and ATF-6, activating them and 1 restructuring the UPR mechanism. Once activated, UPR alleviates protein load by halting transcription, slowing translation, and targeting misfolded proteins for degradation [279]. However, chronic ER stress can deleteriously affect cells and tissues by activating the inflammatory and apoptotic pathways [280]. ER stress has been implicated in the pathogenesis of several obesity-related disorders including diabetes, atherosclerosis, and endothelial dysfunction [281-283]. Recent studies have linked microRNAs to the UPR pathway [284]. In this section, we will dissect the different pathways that link miRNAs and ER stress in regard to obesity-induced endothelial dysfunction (Fig. 7).

GRP78/BIP, a major ER chaperone protein, is critical for protein quality control and has been described as a master regulator of ER stress because of its anti-apoptotic properties [285]. Recent evidence has indicated GRP78/BIP as a novel regulator of vascular endothelial dysfunction [286, 287]. Several miRNAs, including miR-30d, miR-181a, and miR-199a, directly target GRP78/BIP [288]. In several sections prior, we have discussed the potential involvement of each of these miRNAs in the pathogenesis of obesity-induced endothelial dysfunction [58, 182, 188, 224, 225].

MiR-204 affects ER-stress in human cells [289] by directly targeting and inhibiting PERK signaling and thereby causing ER-stress-induced cell death [290]. Our group has previously demonstrated that an increase in miR-204 expression in ECs during obesity is associated with increased ER stress, while inhibition of miR-204 downregulates ER stress and restores endothelial function [91].
The transcriptional factor ATF 4, located downstream of PERK, has been implicated in microvascular endothelial regulation pathways [291] and is suggested to have a role in the pathologic angiogenesis in atherosclerotic plaques [292]. This transcription factor is targeted and inhibited by miR-214 [293]. MiR-214 regulates endothelial function and is altered in obesity [294, 295]. Another miR that is notable for its effects on ATF 4 is miR-663. Inhibition of miR-663 in aortic and venous ECs reduces ATF 4 levels [296], indicating that this miRNA may regulate expression of ATF 4. This microRNA has been linked to atherosclerosis [297] and demonstrated to regulate flow conditions, such as oscillatory shear in ECs, which is believed to contribute to atherosclerosis [298].

CCAAT-enhancer-binding protein homologous protein (CHOP), a proapoptotic transcription factor that is involved in the downstream cascade of ATF 4 [299], is a target of miR-211 [300]. While the circulatory levels of miR-211 are found to be increased in patients with atherosclerosis [301], no evidence has linked miR-211 to endothelial function, despite the extensive number of studies establishing the interconnection between CHOP, ER stress, atherosclerosis and endothelial dysfunction [302]. We believe that further exploring the role of miR211 in the pathogenesis of obesity-induced endothelial dysfunction through ER stress pathways will uncover new mechanisms and offer a better understanding of the pathology.

A part of the UPR, IRE1 $\alpha$ is regulated by miR-1291 [303]. Although little is known about its involvement in the obesity-induced vascular damage pathogenesis, miR1291 has been shown to be increased in patients with myocardial infarction [304], a disease whose incidence is augmented by obesity [305] and is linked to endothelial dysfunction [306]. 


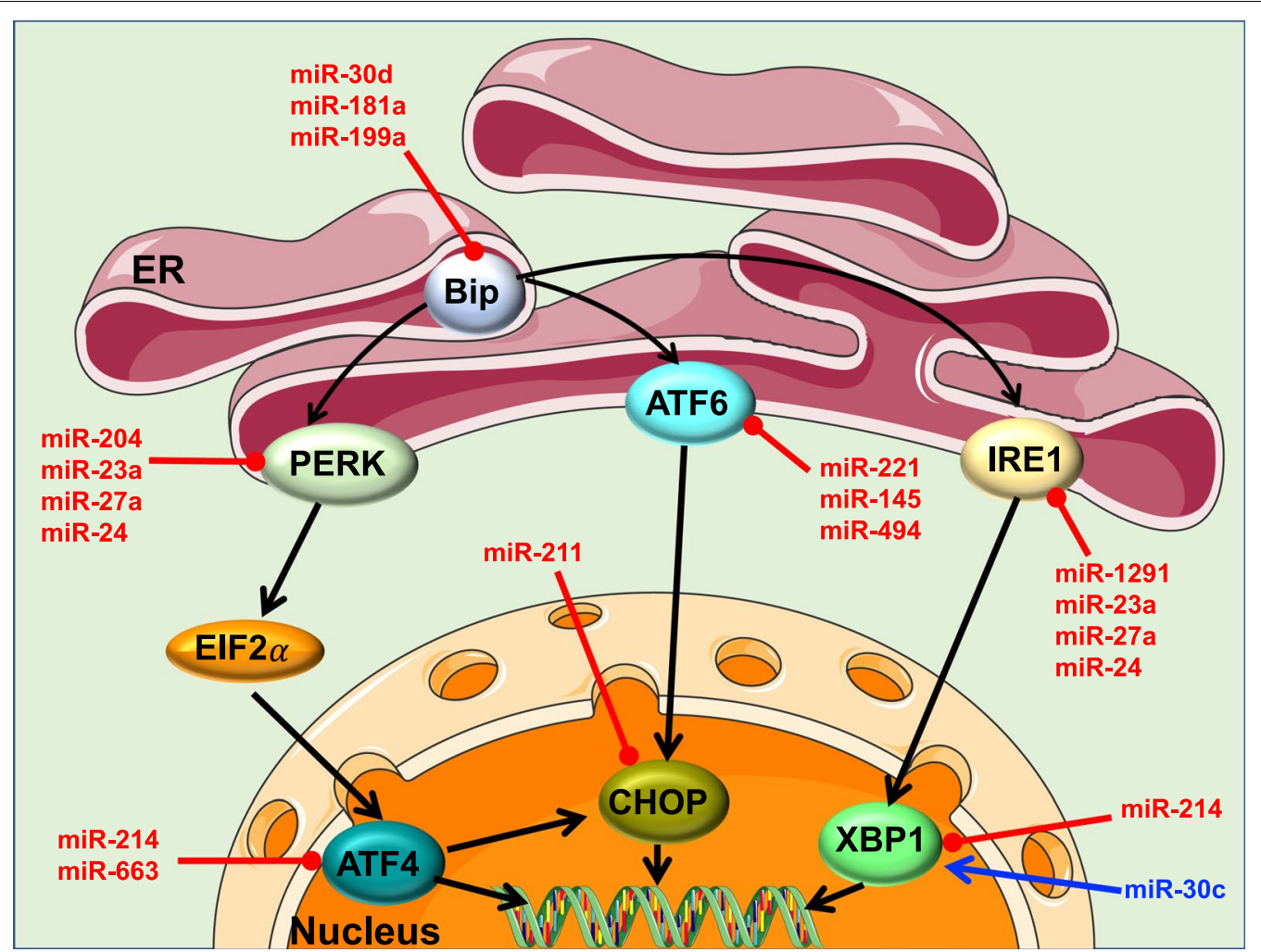

Fig. 7 Obesity, ER stress, miRNAs and endothelial function. Under ER stress, BIP will activate the three UPR sensor pathways that are initiated by PERK, ATF6, and IRE1. MicroRNAs involved in the UPR pathway and evidenced linkage to obesity and endothelial dysfunction are listed in this diagram. miR-30d, miR-181a, and miR-199a-5p have all been shown to directly target BIP. MiR-204, miR-23a, miR-27a and miR-24 directly target and inhibit PERK signaling, which then causes ER-stress-induced cell death. ATF4, located downstream of PERK, is directly inhibited by miR-214 and miR-663. CHOP, which is regulated by ATF4, is suppressed by miR-211. IRE1 $a$ and its downstream signaling XBP1 make up the second arm of the UPR; the former is targeted by miR-1291, miR-23a, miR-27a and miR-24, while the latter is targeted by miR-214. Finally, in the third arm of UPR, miR-221, miR-145 and miR-494 directly target ATF6. ER: endoplasmic reticulum; ATF6: Activating transcription factor 6; IRE1 a inositol requiring enzyme 1 alpha; and PERK protein kinase-like ER kinase; BIP: Binding Immunoglobulin Protein, also known as GRP78; UPR: unfolded protein response, ATF 4: Activating transcription factor 4; CHOP: CCAAT-enhancer-binding protein homologous protein; XBP1: X box binding protein 1; El2 a: Eukaryotic Initiation Factor 2 alpha

In the downstream signaling cascade, $\mathrm{X}$-box binding protein 1 (XBP1) is a target of miR-214 and miR-30c [307, 308]. The implication of both miR-214 and miR-30c in the process of obesity-induced endothelial damage has been discussed earlier in this review.

Induction of the miR-23a-27a-24 cluster activates PERK and IRE1, which then leads to perturbation in intracellular calcium levels and mitochondrial function [309]. As mentioned above, miR-23a and miR-24 are associated to the pathogenesis of obesity and vascular endothelial damage $[54,55,58,63,260,261]$. miR-27a is upregulated during obesity [310] and involved in atherosclerosis [311].

As the third arm of the UPR, ATF6 is not spared from miRNA regulation. MiR-221, miR-145 and miR-494 are shown to be strong candidates in this matter [312]. Interestingly, miR-221 is elevated during obesity [313] and associated to EC dysfunction in the progression of atherosclerosis [314]. Both miR-145 and miR-494 are related to obesity $[315,316]$ and atherosclerosis [317-319].

UPR by itself can exert a regulatory role on miRNAs; this aspect has been well described in the literature but not discussed here [284, 320]. Throughout this section, we have dissected the potential role that miRNAs may play on ER stress to exacerbate obesity-induced vascular damage. With these findings in mind, we believe that manipulation of each miRNA could offer a novel mechanism and therapeutic approach to prevent endothelial dysfunction during obesity. All data are summarized in Table 7.

\section{Challenges associated with clinical application}

The miRNA research field has extensively grown in the last decade; however, the development of miRNA-based therapy remains very challenging. MiRNAs manipulation 
Table 7 MiRNA regulation during obesity, their function in the cardiovascular system and their potential targets in ER stress pathway

\begin{tabular}{|c|c|c|c|c|c|c|}
\hline miRNAs & $\begin{array}{l}\text { Up/downregulation } \\
\text { (Obesity) }\end{array}$ & Refs. & Function & Refs. & Target & Refs. \\
\hline miR-30d & Up & [58] & Unknown & - & GRP78/BIP & [288] \\
\hline miR-181a & Up & {$[225,226]$} & Oxidative stress-induced EC dysfunction & [224] & GRP78/BIP & [288] \\
\hline miR-199a & Up & {$[184,188]$} & EC dysfunction & [185] & GRP78/BIP & [288] \\
\hline miR-204 & Up & {$[44]$} & EC dysfunction & [44] & PERK & {$[289,290]$} \\
\hline miR-214 & Up & {$[294,295]$} & Regulates EC function & {$[294,295]$} & ATF 4, XBP1 & {$[293,307]$} \\
\hline miR-663 & Up & [297] & Regulates oscillatory shear in EC-atherosclerosis & [297] & ATF 4 & [296] \\
\hline miR-211 & Up & [301] & Promotes atherosclerosis & [302] & $\mathrm{CHOP}$ & [300] \\
\hline miR-1291 & Unknown & - & EC dysfunction & {$[305,306]$} & UPR, IRE1a & [303] \\
\hline miR30c & Down & {$[268,269]$} & EC inflammation & {$[268,269]$} & XBP1 & [308] \\
\hline miR-24 & Up & {$[58-60]$} & Exacerbates atherogenesis and plaque formation & {$[62,63]$} & PERK\&IRE1 & [309] \\
\hline miR-23a & Up & [261] & Promotes atherosclerotic plaque formation & [260] & PERK\&IRE1 & [309] \\
\hline miR-27a & Up & [310] & Atherosclerosis formation & [311] & PERK\&IRE1 & [309] \\
\hline miR-221 & Up & [313] & EC dysfunction & [314] & ATF6 & [312] \\
\hline miR-145 & Up & [315] & Promotes atherosclerosis & [317] & ATF6 & [312] \\
\hline miR-494 & Up & [316] & Promotes atherosclerosis & {$[318,319]$} & ATF6 & [312] \\
\hline
\end{tabular}

mainly uses gain- and loss-of-function tools such as miRNA mimics, and antagonists and inhibitors, respectively. The miRNA mimic technology is an innovative approach for overexpressing the mature sequence of the miRNA. Although miRNA mimics are advantageous in that they are easily synthesized and to behave in the same manner as their analog endogenous miRNA, they can lead to undesirable off-target effects because they non-selectively imitate the endogenous miRNA of even normal cells or tissues. The miRNAs antagonists, known as antagomirs, are 22-23nt RNA analogs that have a complementary sequence to the miRNA and silence the miRNA's function. Despite the advantages of nuclease resistance and their easy-delivery system, antagomirs often have off-target effects and induce unexpected side-effects. This occurs mostly because each miRNA can have different targets depending on the cell or tissue type or because other miRNAs are acting on the same mRNA. Few studies have attempted to introduce these tools into clinical practice. One such study involves MRX34, a liposomal miR-34a mimic that is one of the first miRNA mimic to be put to clinical application; in 2013, it was used as miRNA cancer therapy in patients with liver cancer and hematological malignancies [321]. Due to the adverse effects of this miRNA mimic, the study had to be discontinued before it reached phase II of the clinical trial. MRG-201, which mimics miR-29 and was being studied to determine its ability to limit the formation of fibrous scar tissue, has seen more success up until this point [322]. It has successfully passed phase I of the clinical trial, and a phase II clinical trial is soon-to-be initiated, with the purpose of evaluating its efficacy in subjects with fibrotic diseases such as keloids formation.

Within the antagonist and inhibitor category, Miravirsen, a miR-122 inhibitor, has been established to effectively combat hepatitis $C$ viral infection [323]. Miravirsen is currently in phase II of the clinical trial and has shown beneficial outcomes without any notable adverse effects. With its ability to downregulate miR-122, this drug is currently a very promising combatant against hepatitis C. Likewise, MRG-106, a synthetic inhibitor of miR-155 that plays an important role in cutaneous $T$ cell lymphomas, has shown very promising results from phase I of its clinical trial. This has encouraged the investigation of MRG-106 to be continued and to include patients with additional hematological malignancies in which miR-155 is known to be elevated and relevant.

\section{Conclusion and future perspectives}

The evidence that we have presented here in this review, helps to strengthen the concept that miRNAs constitute a good target for a based therapy tool against obesityinduced endothelial damage. However, their multitude of targets and their interplay with different organs and subcellular organelles, makes them very non-specific and therefore prone to unwanted effects, should they be manipulated. Therefore, extensive bench side investigations are essential to harness the therapeutic potential of miRNAs while minimizing undesirable off-target effects. Investigations is most needed at the bench level. The achievement of this goal would constitute a breakthrough in current medicine. 


\section{Abbreviations}

miRNAs: microRNAs; Pol: polymerase; Drosha: ribonuclease III double-stranded RNA-specific endoribonuclease; DGCR8: DiGeorge syndrome chromosomal region 8; Dicer: helicase with RNase motif; TRBP: TAR RNA binding protein; AGO: argonaute protein; RISC: RNA-induced silencing complex; UTR: untranslated region; eNOS: endothelial nitric oxide synthase; SIRT1: NAD-dependent deacetylase sirtuin-1; ER: endoplasmic reticulum; EC: endothelial cells; Cav1: caveolin 1; cGMP: cyclic guanosine monophosphate; TNF-a: Tumor Necrosis Factor; ROS: reactive oxygen species; PGC1a: peroxisome proliferator-activated receptor $\gamma$ coactivator 1 alpha; $\mathrm{O}_{\dot{2}}$ superoxide anion; $\mathrm{NADPH}$ : nicotinamideadenine dinucleotide phosphate; NOX: catalytic, membrane-bound subunit of NADPH oxidase; SODs: superoxide dismutases; GSHPx: glutathione peroxidase; CATs: catalases; PRDXs: peroxiredoxins; ISCU: iron/sulfur cluster assembly enzymes; ULK1: UNC-51-like kinase 1; FIP200: focal adhesion kinase family interacting protein of 200 kDa; VPS34: vacuolar protein sorting 34; PIK3C3: class III phosphatidylinositol 3-kinase; AMPK: 5' adenosine monophosphateactivated protein kinase; mTORC1: mammalian target of rapamycin (mTOR) complex 1; ATG: autophagy-related protein; LC3: microtubule-associated protein 1A/1B-light chain 3; P62: sequestrome 1; FoxO: forkhead box; PGC-1 a: peroxisome proliferator-activated receptor gamma coactivator 1-alpha; UVRAG: UV resistance-associated gene; VAMP8: vesicle-associated membrane protein; STX17: syntaxin; LAMP: lysosome-associated membrane proteins; Rab7: ras-related protein; PE: phosphotidyl-ethanolamine; VEGF: vascular endothelial growth factor; NSF: soluble $\mathrm{N}$-ethylmaleimide sensitive factor; SNARE: Attachment Protein Receptor; UPR: unfolded protein response; PERK: protein kinase R-like ER kinase; IRE 1: inositol-requiring enzyme; ATF 6: activating transcription factor; GRP78/BIP: 78 kDa-glucose-regulated protein/immunoglobulin binding protein; ATF 4: activating transcription factor 4; CHOP: CCAAT-enhancer-binding protein homologous protein; XBP1: X box binding protein 1; El2 a: Eukaryotic Initiation Factor 2 alpha.

\section{Acknowledgements}

Not applicable.

\section{Authors' contributions}

$K A$ and $M K$ conceived of the study with all authors contributing to its design. KA conducted the literature searches. MK, KA, AK, SC, and AG screened the papers to determine eligibility for inclusion in the study and extracted data from the included articles. KA led the extraction of data and drafted the manuscript with input from MG, AK, SK, SC, AG, TK, AMS, CC, and MK. All authors read and approved the final manuscript.

\section{Funding}

M. Kassan is supported by American Heart Association Funding Number AHA-18CDA34030155.

\section{Availability of data and materials \\ Not applicable.}

\section{Ethics approval and consent to participate}

Not applicable.

\section{Consent for publication}

Not applicable.

\section{Competing interests}

The authors declare that they have no competing interests.

\footnotetext{
Author details

${ }^{1}$ Cardiovascular Division, Department of Medicine, and Abboud Cardiovascular Research Center, University of lowa Carver College of Medicine, lowa City, IA 52242, USA. ${ }^{2}$ Skaggs School of Pharmacy and Pharmaceutical Sciences, University of California, San Diego, USA. ${ }^{3}$ Department of Pharmaceutical Sciences, School of Pharmacy, West Coast University, Los Angeles, USA. ${ }^{4}$ Department of Physiology, College of Medicine, Brain Korea 21 PLUS Project for Medical Science, Yonsei University, Seoul, South Korea. ${ }^{5}$ Instituto de Química, Pontificia, Universidad Católica de Valparaíso, Valparaíso, Chile. ${ }^{6}$ Department of Food Science and Agriculture Chemistry, McGill University, Montreal, QC,
}

Canada. ${ }^{7}$ Department of emergency and Critical Care, Shanghai General Hospital, Shanghai Jiao Tong University School of Medicine, Shanghai, China.

Received: 27 April 2020 Accepted: 28 August 2020

Published online: 09 September 2020

\section{References}

1. Khan LK, Bowman B. Obesity: a major global public health problem. Ann Rev Nutr. 1999;19:11.

2. Ogden CL, Carroll MD, Curtin LR, McDowell MA, Tabak CJ, Flegal KMJJ. Prevalence of overweight and obesity in the United States, 1999-2004. JAMA. 2006;295:1549-55.

3. Flegal KM, Carroll MD, Ogden CL, Curtin LRJJ. Prevalence and trends in obesity among US adults, 1999-2008. Jama-J Am Med Assoc. 2010;303:235-41.

4. Flegal KM, Carroll MD, Ogden CL, Johnson CLJJ. Prevalence and trends in obesity among US adults, 1999-2000. Jama-J Am Med Assoc. 2002;288:1723-7.

5. Flegal KM, Carroll MD, Kuczmarski RJ, Johnson CLJ. Overweight and obesity in the United States: prevalence and trends, 1960-1994. Int J Obes Relat Metab Disord. 1998;22:39.

6. Pi-Sunyer XJP. The medical risks of obesity. Postgrad Med. 2009;121:21-33.

7. Jonk AM, Houben AJ, de Jongh RT, Serné EH, Schaper NC, Stehouwer CDJP. Microvascular dysfunction in obesity: a potential mechanism in the pathogenesis of obesity-associated insulin resistance and hypertension. Physiology (Bethesda). 2007;22:252-60.

8. Avogaro A, de Kreutzenberg SV. Mechanisms of endothelial dysfunction in obesity. Clin Chim Acta. 2005;360:9-26.

9. Shankar SS, Steinberg HO. Obesity and endothelial dysfunction. Seminars in vascular medicine: Copyright@ 2005 by Thieme Medical Publishers, Inc., 333 Seventh Avenue, New, 2005. p. 56-64.

10. Echahidi N, Mohty D, Pibarot P, Després J-P, Ohara G, Champagne J, Philippon F, Daleau P, Voisine P, Mathieu PJC. Obesity and metabolic syndrome are independent risk factors for atrial fibrillation after coronary artery bypass graft surgery. Circulation. 2007;116:1213-9.

11. Wanhoutte P. Endothelial dysfunction: the first step toward coronary arterioslerosis. Circ J. 2009;73:595-601.

12. Caballero AEJ. Endothelial dysfunction in obesity and insulin resistance: a road to diabetes and heart disease. Obes Res. 2003;11:1278-89.

13. Petrie JR, Guzik TJ, Touyz RM. Diabetes, hypertension, and cardiovascular disease: clinical insights and vascular mechanisms. Can J Cardiol. 2018;34:575-84.

14. Esteller M. Non-coding RNAs in human disease. Nat Rev Genet. 2011;12:861.

15. Tüfekci KU, Öner MG, Meuwissen RLJ, Genç Ş. The role of microRNAs in human diseases. miRNomics: MicroRNA Biology and Computational Analysis. Berlin: Springer; 2014. p. 33-50.

16. Pordzik J, Jakubik D, Jarosz-Popek J, Wicik Z, Eyileten C, De Rosa S, Indolf C, Siller-Matula JM, Czajka P, Postula M. Significance of circulating microRNAs in diabetes mellitus type 2 and platelet reactivity: bioinformatic analysis and review. Cardiovasc Diabetol. 2019;18:113.

17. lacomino G, Siani AJG. Role of microRNAs in obesity and obesity-related diseases. Genes Nutr. 2017;12:23.

18. Lee RC, Feinbaum RL, Ambros VJ. The C. elegans heterochronic gene lin-4 encodes small RNAs with antisense complementarity to lin-14. Cell. 1993;75:843-54.

19. Pfeffer S, Zavolan M, Grässer FA, Chien M, Russo JJ, Ju J, John B, Enright AJ, Marks D, Sander CJS. Identification of virus-encoded microRNAs. Science. 2004;304:734-6.

20. Bartel DPJ. MicroRNAs: genomics, biogenesis, mechanism, and function Cell. 2004;116:281-97.

21. Kozomara A, Birgaoanu M, Griffiths-Jones S. miRBase: from microRNA sequences to function. Nucleic Acids Res. 2019;47:D155-62.

22. Lewis BP, Shih $\mathrm{I}-\mathrm{H}$, Jones-Rhoades MW, Bartel DP, Burge CBJC. Prediction of mammalian microRNA targets. Cell. 2003;115:787-98.

23. Borchert GM, Lanier W, Davidson BLJ, Biolocfvgy M. RNA polymerase III transcribes human microRNAs. Nat Struct Mol Biol. 2006;13:1097. 
24. Lee $Y$, Kim M, Han J, Yeom KH, Lee S, Baek SH, Kim VN. MicroRNA genes are transcribed by RNA polymerase II. EMBO J. 2004:23:4051-60

25. Lee Y, Ahn C, Han J, Choi H, Kim J, Yim J, Lee J, Provost P, Rådmark O, Kim SJN. The nuclear RNase III Drosha initiates microRNA processing Nature. 2003:425:415

26. Gregory RI, Yan K, Amuthan G, Chendrimada T, Doratotaj B, Cooch N, Shiekhattar RJN. The Microprocessor complex mediates the genesis of microRNAs. Nature. 2004;432:235.

27. Zeng Y, Cullen BR. Efficient processing of primary microRNA hairpins by Drosha requires flanking nonstructured RNA sequences. J Biol Chem. 2005;280:27595-603.

28. Han J, Lee Y, Yeom K-H, Nam J-W, Heo I, Rhee J-K, Sohn SY, Cho Y, Zhang B-T, Kim VNJ. Molecular basis for the recognition of primary microRNAs by the Drosha-DGCR8 complex. Cell. 2006;125:887-901.

29. Yi R, Qin Y, Macara IG, Cullen BRJG. Exportin-5 mediates the nuclear export of pre-microRNAs and short hairpin RNAs. Genes Dev. 2003;17:3011-6.

30. Johanson TM, Lew AM, Chong MM. MicroRNA-independent roles of the RNase III enzymes Drosha and Dicer. Open biology. 2013:3:130144

31. Carthew RW, Sontheimer EJJC. Origins and mechanisms of miRNAs and siRNAs. Cell. 2009;136:642-55.

32. Haase AD, Jaskiewicz L, Zhang H, Lainé S, Sack R, Gatignol A, Filipowicz WJE. TRBP, a regulator of cellular PKR and HIV-1 virus expression, interacts with Dicer and functions in RNA silencing. EMBO Rep. 2005;6:961-7.

33. Chendrimada TP, Gregory RI, Kumaraswamy E, Norman J, Cooch N, Nishikura K, Shiekhattar RJN. TRBP recruits the Dicer complex to Ago2 for microRNA processing and gene silencing. Nature. 2005;436:740.

34. Bonetti PO, Lerman LO, Lerman AJA. Endothelial dysfunction: a marker of atherosclerotic risk. Arterioscler Thromb Vasc Biol. 2003;23:168-75.

35. Lerman A, Burnett JJJC. Intact and altered endothelium in regulation of vasomotion. Circulation. 1992;86:12-9.

36. Lerman A, Zeiher AMJC. Endothelial function: cardiac events. Circulation. 2005;111:363-8.

37. Ignarro LJ. Endothelium-derived nitric oxide: actions and properties. FASEB J. 1989:3:31-6.

38. Vane JR, Änggård EE, Botting RM. Regulatory functions of the vascular endothelium. N Engl J Med. 1990;323:27-36.

39. Yanagisawa M, Kurihara H, Kimura S, Tomobe $Y$, Kobayashi M, Mitsui Y, Yazaki Y, Goto K, Masaki TJ. A novel potent vasoconstrictor peptide produced by vascular endothelial cells. Nature. 1988;332:411.

40. Schechter AN, Gladwin MT. Hemoglobin and the paracrine and endocrine functions of nitric oxide. N Engl J Med. 2003;348:1483-5.

41. Endemann DH, Schiffrin EL. Endothelial dysfunction. J Am Soc Nephrol. 2004;15:1983-92.

42. Stapleton PA, James ME, Goodwill AG, Frisbee JC. Obesity and vascular dysfunction. J Pathophysiol. 2008;15:79-89.

43. Mattagajasingh I, Kim C-S, Naqvi A, Yamamori T, Hoffman TA, Jung S-B, DeRicco J, Kasuno K, Irani KJPS. SIRT1 promotes endothelium-depend ent vascular relaxation by activating endothelial nitric oxide synthase. Proc Natl Acad Sci U S A. 2007;104:14855-60.

44. Vikram A, Kim Y-R, Kumar S, Li Q, Kassan M, Jacobs JS, Irani KJN. Vascular microRNA-204 is remotely governed by the microbiome and impairs endothelium-dependent vasorelaxation by downregulating Sirtuin1. Nat Commun. 2016:7:12565

45. Gamez-Mendez AM, Vargas-Robles H, Ríos A, Escalante BJP. Oxidative stress-dependent coronary endothelial dysfunction in obese mice. PLOS ONE. 2015;10:e0138609.

46. Austin R, Lentz S, Werstuck GJC. Role of hyperhomocysteinemia in endothelial dysfunction and atherothrombotic disease. Cell Death Differ. 2004; 11:S56

47. Kaplon RE, Chung E, Reese L, Cox-York K, Seals DR, Gentile CLJ. Activation of the unfolded protein response in vascular endothelial cells of nondiabetic obese adults. J Clin Endocrinol Metab. 2013;98:E1505-9.

48. Bharath LP, Cho JM, Park S-K, Ruan T, Li Y, Mueller R, Bean T, Reese V, Richardson RS, Cai JJA. Endothelial cell autophagy maintains shear stress-induced nitric oxide generation via glycolysis-dependent purinergic signaling to endothelial nitric oxide synthase. Arterioscler Thromb Vasc Biol. 2017:37:117
49. Iantorno M, Campia U, Di Daniele N, Nistico S, Forleo G, Cardillo C, Tesauro MJJ. Obesity, inflammation and endothelial dysfunction. J Biol Regul Homeost Agents. 2014;28:169-76.

50. Zhang H-N, Xu Q-Q, Thakur A, Alfred MO, Chakraborty M, Ghosh A, Yu X. Endothelial dysfunction in diabetes and hypertension: role of microRNAs and long non-coding RNAs. Life Sci. 2018;213:258-68.

51. Improta AC, Nonaka CKV, Pereira CS, Soares MBP, Macambira SG, Souza BSF. Exercise training-induced changes in MicroRNAs: beneficial regulatory effects in hypertension, type 2 diabetes, and obesity. Int J Mol Sci. 2018;19:3608.

52. Chamorro-Jorganes A, Araldi E, Suárez YJPR. MicroRNAs as pharmacological targets in endothelial cell function and dysfunction. Pharmacol Res. 2013:75:15-27.

53. Sansbury BE, Hill BG. Antiobesogenic role of endothelial nitric oxide synthase. New York: Elsevier; 2014. p. 323-46.

54. Zhang W, Yan L, Li Y, Chen W, Hu N, Wang H, Ou HJM. Roles of miRNA-24 in regulating endothelial nitric oxide synthase expression and vascular endothelial cell proliferation. Mol Cell Biochem. 2015:405:281-9.

55. Li HT, Wang J, Li SF, Cheng L, Tang WZ, Feng YGJM. Upregulation of microRNA-24 causes vasospasm following subarachnoid hemorrhage by suppressing the expression of endothelial nitric oxide synthase. Mol Med Rep. 2018;18:1181-7.

56. Zheng Y, Li Y, Liu G, Qi X, Cao X. MicroRNA-24 inhibits the proliferation and migration of endothelial cells in patients with atherosclerosis by targeting importin-a3 and regulating inflammatory responses. J Exp Ther Med. 2018;15:338-44.

57. Chen W, Ou HJS. Regulation of miR-24 on vascular endothelial cell function and its role in the development of cardiovascular disease. Sheng Li Xue Bao. 2016;68:201-6.

58. Lopez YON, Garufi G, Pasarica M, Seyhan AAJE. Elevated and correlated expressions of mir-24, mir-30d, mir-146a, and sfrp-4 in human abdominal adipose tissue play a role in adiposity and insulin resistance. Int J Endocrinol. 2018;2018:7351902.

59. Wang M, Li L, Liu R, Song Y, Zhang X, Niu W, Kumar AK, Guo Z, Hu ZJG. Obesity-induced overexpression of miRNA-24 regulates cholesterol uptake and lipid metabolism by targeting SR-B1. Gene. 2018;668:196-203.

60. Sangiao-Alvarellos S, Pena-Bello L, Manfredi-Lozano M, Tena-Sempere M, Cordido FJE. Perturbation of hypothalamic microRNA expression patterns in male rats after metabolic distress: impact of obesity and conditions of negative energy balance. Endocrinology. 2014;155:1838-50.

61. Lovren F, Teoh H, Verma SJC. Obesity and atherosclerosis: mechanistic insights. Can J Cardiol. 2015;31:177-83.

62. Kawashima S, Yokoyama MJA. Dysfunction of endothelial nitric oxide synthase and atherosclerosis. Arterioscler Thromb Vasc Biol. 2004;24:998-1005.

63. Ren K, Zhu X, Zheng Z, Mo ZC, Peng XS, Zeng YZ, Ou HX, Zhang QH, Qi HZ, Zhao GJJA. MicroRNA-24 aggravates atherosclerosis by inhibiting selective lipid uptake from HDL cholesterol via the post-transcriptional repression of scavenger receptor class B type I. Atherosclerosis. 2018;270:57-67.

64. Sun H-X, Zeng D-Y, Li R-T, Pang R-P, Yang H, Hu Y-L, Zhang Q, Jiang $Y$, Huang $L-Y$, Tang $Y-B$. Essential role of microRNA-155 in regulating endothelium-dependent vasorelaxation by targeting endothelial nitric oxide synthase. J Hypertension. 2012;60:1407-14.

65. Karkeni E, Astier J, Tourniaire F, Abed M, Romier B, Gouranton E, Wan L, Borel P, Salles J, Walrand SJTE. Obesity-associated inflammation induces microRNA-155 expression in adipocytes and adipose tissue: outcome on adipocyte function. J Clin Endocrinol Metab. 2016;101:1615-26.

66. Zheng C, Zhang J, Chen X, Zhang J, Ding X, You X, Fan L, Chen C, Zhou Y. MicroRNA-155 mediates obesity-induced renal inflammation and dysfunction. Inflammation. 2019;42:994-1003.

67. Guo Q, Zhang H, Zhang B, Zhang E, Wu Y. Tumor Necrosis Factor-alpha (TNF-a) Enhances miR-155-Mediated Endothelial Senescence by Targeting Sirtuin 1 (SIRT1). Med Sci Monit. 2019;25:8820.

68. Virdis A, Colucci R, Bernardini N, Blandizzi C, Taddei S, Masi S. Microvascular endothelial dysfunction in human obesity: role of TNF-a. J Clin Endocrinol Metab. 2019;104:341-8.

69. Picchi A, Gao X, Belmadani S, Potter BJ, Focardi M, Chilian WM, Zhang CJC. Tumor necrosis factor-a induces endothelial dysfunction in the prediabetic metabolic syndrome. Circ Res. 2006;99:69-77. 
70. Sun X, Lv H, Zhao P, He J, Cui Q, Wei M, Feng S, Zhu Y. Commutative regulation between endothelial $\mathrm{NO}$ synthase and insulin receptor substrate 2 by microRNAs. J Mol Cell Biol. 2018;8:9.

71. Yang WM, Jeong HJ, Park SW, Lee WJM. Obesity-induced miR-15b is linked causally to the development of insulin resistance through the repression of the insulin receptor in hepatocytes. Mol Nutr Food 2015:59:2303-14.

72. Ortega FJ, Mercader JM, Catalán V, Moreno-Navarrete JM, Pueyo N, Sabater M, Gómez-Ambrosi J, Anglada R, Fernández-Formoso JA, Ricart W. Targeting the circulating microRNA signature of obesity. Clin Chem. 2013;59:781-92

73. Wang $H$, Zhang $P$, Chen W, Feng D, Jia Y, Xie L-X. Evidence for serum miR-15a and miR-16 levels as biomarkers that distinguish sepsis from systemic inflammatory response syndrome in human subjects. Clin Chem Lab Med. 2012;50:1423-8.

74. Muniyappa R, Sowers JRJRE. Role of insulin resistance in endothelial dysfunction. Rev Endocr Metab Disord. 2013;14:5-12.

75. Chistiakov DA, Sobenin IA, Orekhov AN, Bobryshev YVJB. Human miR-221/222 in physiological and atherosclerotic vascular remodeling Biomed Res Int. 2015:2015:354517.

76. Ho JD, Robb GB, Tai SC, Turgeon PJ, Mawji IA, Man HJ, Marsden PA. Active stabilization of the human eNOS mRNA by hnRNP E1 protects against antisense RNA and microRNAs. Mol Cell Biol. 2013;8:01257.

77. Liao YC, Wang YS, Hsi E, Chang MH, You YZ, Juo SHH. MicroRNA-765 influences arterial stiffness through modulating apelin expression. Mol Cell Endocrinol. 2015;411:11-9.

78. Sayed ASM, Xia K, Li F, Deng X, Salma U, Li T, Deng H, Yang D, Haoyang $Z$, Yang TJC. The diagnostic value of circulating microRNAs for middleaged (40-60-year-old) coronary artery disease patients. Clinics (Sao Paulo). 2015;70:257-63.

79. Jahangir E, De Schutter A, Lavie CJ. The relationship between obesity and coronary artery disease. Transl Res. 2014;164:336-44.

80. Romero-Corral A, Montori VM, Somers VK, Korinek J, Thomas RJ, Allison TG, Mookadam F, Lopez-Jimenez FJTL. Association of bodyweight with total mortality and with cardiovascular events in coronary artery disease: a systematic review of cohort studies. Lancet. 2006;368:666-78.

81. Martin JL, Jia G, Martin SS, Shapiro TA, Herrmann HC, DiBattiste PM, Topol EJ, Moliterno DJJC. The relationship of obesity to ischemic outcomes following coronary stent placement in contemporary practice. Catheter Cardiovasc Interv. 2006;67:563-70.

82. Sayed D, Abdellatif MJCC. AKT-ing via microRNA. Cell Cycle. 2010;9:3233-7.

83. Sun X, Lin J, Zhang Y, Kang S, Belkin N, Wara AK, Icli B, Hamburg NM, Li D, Feinberg MW. MicroRNA-181b improves glucose homeostasis and insulin sensitivity by regulating endothelial function in white adipose tissue. Circ Res. 2016;118:810-21.

84. Jia G, Sowers JRJD. Caveolin-1 in cardiovascular disease: a doubleedged sword. Diabetes. 2015;64:3645-7.

85. Gu Y, Cai R, Zhang C, Xue Y, Pan Y, Wang J, Zhang Z. miR-132-3p boosts caveolae-mediated transcellular transport in glioma endothelial cells by targeting PTEN/PI3K/PKB/Src/Cav-1 signaling pathway. FASEB J. 2018;33:441-54

86. Kang Q, Xiang Y, Li D, Liang J, Zhang X, Zhou F, Qiao M, Nie Y, He Y, Cheng J. MiR-124-3p attenuates hyperphosphorylation of Tau proteininduced apoptosis via caveolin-1-PI3K/Akt/GSK3 3 pathway in N2a/ APP695swe cells. Oncotarget. 2017;8:24314.

87. Vaquero A, Scher M, Lee D, Erdjument-Bromage H, Tempst P, Reinberg DJM. Human SirT1 interacts with histone $\mathrm{H} 1$ and promotes formation of facultative heterochromatin. Mol Cell. 2004;16:93-105.

88. Prozorovski T, Schulze-Topphoff U, Glumm R, Baumgart J, Schröter F, Ninnemann O, Siegert E, Bendix I, Brüstle O, Nitsch RJN. Sirt1 contributes critically to the redox-dependent fate of neural progenitors. Nat Cell Biol. 2008;10:385.

89. Schug TT, Li XJA. Sirtuin 1 in lipid metabolism and obesity. Ann Med 2011;43:198-211.

90. Bordone L, Guarente LN. Calorie restriction, SIRT1 and metabolism: understanding longevity. Nat Rev Mol Cell Biol. 2005;6:298.

91. Kassan M, Vikram A, Kim Y-R, Li Q, Kassan A, Patel HH, Kumar S, Gabani M, Liu J, Jacobs JS. Sirtuin 1 protects endothelial Caveolin-1 expression and preserves endothelial function via suppressing miR-204 and endoplasmic reticulum stress. Scientific reports. 2017:7:42265.
92. D'Onofrio N, Servillo L, Balestrieri MLJA. SIRT1 and SIRT6 signaling pathways in cardiovascular disease protection. Antioxid Redox Signal. 2018:28:711-32.

93. Orimo M, Minamino T, Miyauchi H, Tateno K, Okada S, Moriya J, Komuro IJA. Protective role of SIRT1 in diabetic vascular dysfunction. Arterioscler Thromb Vasc Biol. 2009;29:889-94.

94. Kitada M, Ogura Y, Koya DJA. The protective role of Sirt1 in vascular tissue: its relationship to vascular aging and atherosclerosis. Aging (Albany NY). 2016;8:2290.

95. Metoyer CF, Pruitt KJP. The role of sirtuin proteins in obesity. Pathophysiology. 2008;15:103-8.

96. Barton MJPA. Obesity and aging: determinants of endothelial cell dysfunction and atherosclerosis. Pflugers Arch. 2010;460:825-37.

97. Wang C-Y, Kim H-H, Hiroi Y, Sawada N, Salomone S, Benjamin LE, Walsh K, Moskowitz MA, Liao JKJ. Obesity increases vascular senescence and susceptibility to ischemic injury through chronic activation of Akt and mTOR. Sci Signal. 2009;2:11.

98. Menghini R, Casagrande V, Cardellini M, Martelli E, Terrinoni A, Amati F, Vasa-Nicotera M, Ippoliti A, Novelli G, Melino G. MicroRNA 217 modulates endothelial cell senescence via silent information regulator 1. Circulation. 2009;120:1524-32.

99. Ito T, Yagi S, Yamakuchi MJB. MicroRNA-34a regulation of endothelial senescence. Biochem Biophys Res Commun. 2010;398:735-40.

100. Choi SE, Fu T, Seok S, Kim DH, Yu E, Lee KW, Kang Y, Li X, Kemper B, Kemper JKJA. Elevated microRNA-34a in obesity reduces NAD + levels and SIRT1 activity by directly targeting NAMPT. Aging Cell. 2013;12:1062-72.

101. Zhang L, Chen J, He Q, Chao Z, Li X, Chen M. MicroRNA-217 is involved in the progression of atherosclerosis through regulating inflammatory responses by targeting sirtuin 1. Mol Med Rep. 2019;20:3182-90.

102. Yuan J, Chen M, Xu Q, Liang J, Chen R, Xiao Y, Fang M, Chen LJCP. Effect of the Diabetic Environment On the Expression of MiRNAs in Endothelial Cells: Mir-149-5p restoration ameliorates the high glucose-induced expression of TNF-a and ER stress markers. Cell Physiol Biochem. 2017:43:120-35

103. Mohamed JS, Hajira A, Pardo PS, Boriek AMJD. MicroRNA-149 inhibits PARP-2 and promotes mitochondrial biogenesis via SIRT-1/PGC-1a network in skeletal muscle. Diabetes. 2014;63:1546-59.

104. Kadlec AO, Chabowski DS, Ait-Aissa K, Gutterman DDJA. Role of PGC-1a in vascular regulation: implications for atherosclerosis. Arterioscler Thromb Vasc Biol. 2016;36:1467-74.

105. Ahmadpour F, Nourbakhsh M, Razzaghy-Azar M, Khaghani S, Alipoor B, Abdolvahabi Z, Zangoei M. The association of plasma levels of mir-34a and mir-149 with obesity and insulin resistance in obese children and adolescents. Acta Endocrinol-Buch. 2018;14:149-54.

106. Strum JC, Johnson JH, Ward J, Xie H, Feild J, Hester A, Alford A, Waters KM. MicroRNA 132 regulates nutritional stress-induced chemokine production through repression of SirT1. Mol Endocrinol. 2009:23:1876-84.

107. Heneghan H, Miller N, McAnena O, O'brien T, Kerin M. Differential miRNA expression in omental adipose tissue and in the circulation of obese patients identifies novel metabolic biomarkers. J Clin Endocrinol Metab. 2011;96:E846-E850.

108. Zhang L, Huang D, Wang Q, Shen D, Wang Y, Chen B, Zhang J, Gai L. MiR-132 inhibits expression of SIRT1 and induces pro-inflammatory processes of vascular endothelial inflammation through blockade of the SREBP-1c metabolic pathway. Cardiovasc Drugs Ther. 2014;28:303-11.

109. Kwaifa IK, Bahari H, Yong YK, Noor SM. Endothelial dysfunction in obesity-induced inflammation: molecular mechanisms and clinical implications. Biomolecules. 2020;10:291.

110. Kalyanaraman BJR. Teaching the basics of redox biology to medical and graduate students: oxidants, antioxidants and disease mechanisms. Redox Biol. 2013;1:244-57

111. Murphy MPJB. How mitochondria produce reactive oxygen species. Biochem J. 2009:417:1-13.

112. Dröse S, Brandt UJJ. The mechanism of mitochondrial superoxide production by the cytochrome bc1 complex. J Biol Chem. 2008;283:21649-54

113. Lenaz GJl. The mitochondrial production of reactive oxygen species: mechanisms and implications in human pathology. IUBMB Life. 2001:52:159-64. 
114. Kowaltowski AJ, de Souza-Pinto NC, Castilho RF, Vercesi AEJ. Mitochondria and reactive oxygen species. Free Radic Biol Med. 2009;47:333-43.

115. Manea A. NADPH oxidase-derived reactive oxygen species: involvement in vascular physiology and pathology. J Cell Tissue Res. 2010:342:325-39.

116. Limón-Pacheco J, Gonsebatt M, Mutagenesis E. The role of antioxidants and antioxidant-related enzymes in protective responses to environmentally induced oxidative stress. Mutat Res. 2009;674:137-47.

117. Andreyev AY, Kushnareva YE, Starkov AJB. Mitochondrial metabolism of reactive oxygen species. Biochemistry (Mosc). 2005;70:200-14.

118. Johnson F, Giulivi C. Superoxide dismutases and their impact upon human health. Mol Aspects Med. 2005;26:340-52.

119. Betteridge DJJM. What is oxidative stress? Metabolism. 2000;49:3-8.

120. Hulsmans M, De Keyzer D, Holvoet PJT. MicroRNAs regulating oxidative stress and inflammation in relation to obesity and atherosclerosis. FASEB J. 2011;25:2515-27.

121. Magenta A, Greco S, Gaetano C, Martelli FJI. Oxidative stress and microRNAs in vascular diseases. Int J Mol Sci. 2013;14:17319-46.

122. Genova ML, Ventura B, Giuliano G, Bovina C, Formiggini G, Castelli GP, Lenaz $\mathrm{G}$. The site of production of superoxide radical in mitochondrial Complex I is not a bound ubisemiquinone but presumably iron-sulfur cluster N2. FEBS Lett. 2001;505:364-8.

123. Tong $\mathbf{W}-\mathrm{H}$, Rouault TAJC. Functions of mitochondrial ISCU and cytosolic ISCU in mammalian iron-sulfur cluster biogenesis and iron homeostasis. Cell Metab. 2006;3:199-210.

124. Chan SY, Zhang Y-Y, Hemann C, Mahoney CE, Zweier JL, Loscalzo JJC. MicroRNA-210 controls mitochondrial metabolism during hypoxia by repressing the iron-sulfur cluster assembly proteins ISCU1/2. Cell Metab. 2009;10:273-84.

125. Li Y, Yang C, Zhang L, Yang PJC. MicroRNA-210 induces endothelial cell apoptosis by directly targeting PDK1 in the setting of atherosclerosis. Cell Mol Biol Lett 2017;22:3.

126. Fasanaro P, D'Alessandra Y, Di Stefano V, Melchionna R, Romani S, Pompilio G, Capogrossi MC, Martelli FJJ. MicroRNA-210 modulates endothelial cell response to hypoxia and inhibits the receptor tyrosine kinase ligand Ephrin-A3. J Biol Chem. 2008;283:15878-83.

127. Raitoharju E, Lyytikäinen L-P, Levula M, Oksala N, Mennander A, Tarkka M, Klopp N, Illig T, Kähönen M, Karhunen PJJA. miR-21, miR-210, miR-34a, and miR-146a/b are up-regulated in human atherosclerotic plaques in the Tampere Vascular Study. Atherosclerosis. 2011;219:211-7.

128. Wang Y, Pan X, Fan Y, Hu X, Liu X, Xiang M, Wang J. Dysregulated expression of microRNAs and mRNAs in myocardial infarction. Am J Transl Res. 2015;7:2291.

129. Gong Y-Y, Luo J-Y, Wang L, Huang YJA. MicroRNAs regulating reactive oxygen species in cardiovascular diseases. Antioxid Redox Signal. 2018;29:1092-107.

130. Keller P, Gburcik V, Petrovic N, Gallagher IJ, Nedergaard J, Cannon B, Timmons JA. Gene-chip studies of adipogenesis-regulated microRNAs in mouse primary adipocytes and human obesity. BMC Endocr Disord. $2011 ; 11: 7$

131. Guglielmi V, D’Adamo M, Menghini R, Cardellini M, Gentileschi P, Federici M, Sbraccia P. MicroRNA 21 is up-regulated in adipose tissue of obese diabetic subjects. Nutr Healthy Aging. 2017:4:141-5.

132. Zhang $X, N g$ W-L, Wang $P$, Tian L, Werner E, Wang H, Doetsch $P$, Wang YJC. MicroRNA-21 modulates the levels of reactive oxygen species by targeting SOD3 and TNFa. Cancer Res. 2012;72:4707-13.

133. La Sala L, Mrakic-Sposta S, Tagliabue E, Prattichizzo F, Micheloni S, Sangalli E, Specchia C, Uccellatore AC, Lupini S, Spinetti G. Circulating microRNA-21 is an early predictor of ROS-mediated damage in subjects with high risk of developing diabetes and in drug-naïve T2D. Cardiovasc Diabetol. 2019;18:18.

134. Xu X, Wells A, Padilla MT, Kato K, Kim KC, Lin YJC. A signaling pathway consisting of miR-551b, catalase and MUC1 contributes to acquired apoptosis resistance and chemoresistance. Carcinogenesis. 2014;35:2457-66.

135. Wang P, Zhu C-F, Ma M-Z, Chen G, Song M, Zeng Z-L, Lu W-H, Yang J, Wen S, Chiao PJJO. Micro-RNA-155 is induced by K-Ras oncogenic signal and promotes ROS stress in pancreatic cancer. Oncotarget. 2015;6:21148

136. Lynch SM, Frei B, Morrow JD, Roberts LJ, Xu A, Jackson T, Reyna R, Klevay LM, Vita JA, Keaney Jr JFJA. Vascular superoxide dismutase deficiency impairs endothelial vasodilator function through direct inactivation of nitric oxide and increased lipid peroxidation. Arterioscl Throm Vas. 1997:17:2975-81.

137. Han J, Shuvaev W, Muzykantov VRP, Therapeutmics E. Catalase and superoxide dismutase conjugated with platelet-endothelial cell adhesion molecule antibody distinctly alleviate abnormal endothelial permeability caused by exogenous reactive oxygen species and vascular endothelial growth factor. J Pharmacol Exp Ther. 2011;338:82-91.

138. Leff JA, Oppegard MA, Terada LS, McCarty EC, Repine JEJ. Human serum catalase decreases endothelial cell injury from hydrogen peroxide. J Appl Physiol. 1985;1991(71):1903-6.

139. Dong R, Zhang K, Wang Y-L, Zhang F, Cao J, Zheng J-B, Zhang H. MiR-551b-5p Contributes to pathogenesis of Vein Graft failure via upregulating early growth response-1 expression. Chin Med J (Engl). 2017;130:1578.

140. Kuryłowicz A, Wicik Z, Owczarz M, Jonas MI, Kotlarek M, Świerniak M, Lisik W, Jonas M, Noszczyk B, Puzianowska-Kuźnicka MJI. NGS Reveals Molecular Pathways Affected by Obesity and Weight Loss-Related Changes in miRNA Levels in Adipose Tissue. Int J Mol Sci. 2017;19:66.

141. Zhang H, Liu J, Qu D, Wang L, Luo J-Y, Lau CW, Liu P, Gao Z, Tipoe GL, Lee HKJD. Inhibition of miR-200c restores endothelial function in diabetic mice through suppression of COX-2. Diabetes. 2016;65:151067.

142. Masotti A, Baldassarre A, Fabrizi M, Olivero G, Loreti M, Giammaria P, Veronelli P, Graziani M, Manco MJP. Oral glucose tolerance test unravels circulating miRNAs associated with insulin resistance in obese preschoolers. Pediatr Obes. 2017;12:229-38.

143. Cui X, You L, Zhu L, Wang X, Zhou Y, Li Y, Wen J, Xia Y, Wang X, Ji CJM. Change in circulating microRNA profile of obese children indicates future risk of adult diabetes. Metabolism. 2018;78:95-105.

144. Cortez MA, Valdecanas D, Zhang X, Zhan Y, Bhardwaj V, Calin GA, Komaki R, Giri DK, Quini CC, Wolfe TJMT. Therapeutic delivery of miR-200c enhances radiosensitivity in lung cancer. Mol Ther. 2014:22:1494-503.

145. Magenta A, Cencioni C, Fasanaro P, Zaccagnini G, Greco S, Sarra-Ferraris G, Antonini A, Martelli F, Capogrossi MJC. miR-200c is upregulated by oxidative stress and induces endothelial cell apoptosis and senescence via ZEB1 inhibition. Cell Death and Differentiation. 2011;18:1628.

146. Wang K-C, Garmire LX, Young A, Nguyen P, Trinh A, Subramaniam S, Wang N, Shyy JY, Li Y-S, Chien SJPS. Role of microRNA-23b in flowregulation of $\mathrm{Rb}$ phosphorylation and endothelial cell growth. Proc Natl Acad Sci U S A. 2010;107:3234-9.

147. He HC, Zhu JG, Chen B, Chen SM, Han ZD, Dai QS, Ling XH, Fu X, Lin ZY, Deng Y. MicroRNA-23b downregulates peroxiredoxin III in human prostate cancer. FEBS Lett. 2012;586:2451-8.

148. He LP, Zhao XS, He LP. Abnormally expressed miR-23b in Chinese Mongolian at high cardiovascular risk may contribute to monocyte/ macrophage inflammatory reaction in atherosclerosis. Bioscience Rep. 2018;38:20180673.

149. Xu Z, Zhang Y, Ding J, Hu W, Tan C, Wang M, Tang J, Xu NA. miR-17-3p Downregulates Mitochondrial Antioxidant Enzymes and Enhances the Radiosensitivity of Prostate Cancer Cells. Mol Ther Nucleic Acids. 2018;13:64-77.

150. Suárez Y, Wang C, Manes TD, Pober JSJ. Cutting edge: TNF-induced microRNAs regulate TNF-induced expression of E-selectin and intercellular adhesion molecule-1 on human endothelial cells: feedback control of inflammation. J Immunol. 2010;184:21-5.

151. Karolina D, Silambarasan M, Armugam A, Yeyaseelan K. MicroRNA and Endothelial Dysfunction in relation to Ob esity and Type2 Diabetes. J Mol genet med S. 2014;1:1747-862.

152. Chen J, Xu L, Hu Q, Yang S, Zhang B, Jiang HJI. MiR-17-5p as circulating biomarkers for the severity of coronary atherosclerosis in coronary artery disease. Int J Cardiol. 2015;197:123-4.

153. Ouyang Y-B, Stary CM, White RE, Giffard RGJA, Signaling R. The use of microRNAs to modulate redox and immune response to stroke. Antioxid Redox Sign. 2015;22:187-202.

154. Kurtz CL, Peck BC, Fannin EE, Beysen C, Miao J, Landstreet SR, Ding S, Turaga V, Lund PK, Turner SJD. MicroRNA-29 fine-tunes the expression of key FOXA2-activated lipid metabolism genes and is dysregulated in animal models of insulin resistance and diabetes. Diabetes. 2014:63:3141-8. 
155. Silambarasan M, Tan J, Karolina D, Armugam A, Kaur C, Jeyaseelan KJI. MicroRNAs in hyperglycemia induced endothelial cell dysfunction. Int J Mol Sci. 2016;17:518.

156. Martinez I, Cazalla D, Almstead LL, Steitz JA, DiMaio D. miR-29 and miR-30 regulate B-Myb expression during cellular senescence. Proc Natl Acad Sci USA. 2011;108:522-7.

157. Bedard K, Krause K-H. The NOX family of ROS-generating NADPH oxidases: physiology and pathophysiology. J Physiol Rev. 2007;87:245-313.

158. Serrander L, Cartier L, Bedard K, Banfi B, Lardy B, Plastre O, Sienkiewicz A, Fórró L, Schlegel W, Krause K. NOX4 activity is determined by mRNA levels and reveals a unique pattern of ROS generation. Biochem $\mathrm{J}$. 2007:406:105-14.

159. El-Benna J, Dang PM-C, Gougerot-Pocidalo M-A, Marie J-C, BrautBoucher FJE. p47phox, the phagocyte NADPH oxidase/NOX2 organizer: structure, phosphorylation and implication in diseases. Exp Mol Med. 2009;41:217.

160. Lynch CM, Kinzenbaw DA, Chen X, Zhan S, Mezzetti E, Filosa J, Ergul A, Faulkner JL, Faraci FM, Didion SPJS. Nox2-derived superoxide contributes to cerebral vascular dysfunction in diet-induced obesity. Stroke. 2013:44:3195-201.

161. Kyrychenko S, Kyrychenko V, Badr MA, Ikeda Y, Sadoshima J, Shirokova NJC. Pivotal role of miR-448 in the development of ROS-induced cardiomyopathy. Cardiovasc Res. 2015;108:324-34.

162. Wang Y, Wang D-S, Cheng Y-S, Jia B-L, Yu G, Yin X-Q, Wang YJCP. Expression of MicroRNA-448 and SIRT1 and Prognosis of Obese Type 2 Diabetic Mellitus Patients After Laparoscopic Bariatric Surgery. Cell Physiol Biochem. 2018;45:935-50.

163. Kinoshita M, Ono K, Horie T, Nagao K, Nishi H, Kuwabara Y, TakanabeMori R, Hasegawa K, Kita T, Kimura TJM. Regulation of adipocyte differentiation by activation of serotonin (5-HT) receptors 5-HT2AR and 5-HT2CR and involvement of microRNA-448-mediated repression of KLF5. Mol Endocrinol. 2010;24:1978-87.

164. Wang T, Liu Y-P, Wang T, Xu B-Q, Xu BJB. ROS feedback regulates the microRNA-19-targeted inhibition of the p47phox-mediated LPSinduced inflammatory response. Biochem Biophys Res Commun. 2017:489:361-8.

165. Tang Y, Zhang Y-C, Chen Y, Xiang Y, Shen C-X, Li Y-S. The role of miR-19b in the inhibition of endothelial cell apoptosis and its relationship with coronary artery disease. Sci Rep. 2015;5:15132.

166. Hsieh C-H, Rau C-S, Wu S-C, Yang JC-S, Wu Y-C, Lu T-H, Tzeng S-L, Wu C-J, Lin C-WJB. Weight-reduction through a low-fat diet causes differential expression of circulating microRNAs in obese C57BL/6 mice. Bmc Genomics. 2015;16:699.

167. Li T-B, Zhang Y-Z, Liu W-Q, Zhang J-J, Peng J, Luo X-J, Ma Q. Correlation between NADPH oxidase-mediated oxidative stress and dysfunction of endothelial progenitor cell in hyperlipidemic patients. Korean J Intern Med. 2018:33:313.

168. Den Hartigh LJ, Omer M, Goodspeed L, Wang S, Wietecha T, O'brien KD, Han CYJA. Adipocyte-specific deficiency of NADPH oxidase 4 delays the onset of insulin resistance and attenuates adipose tissue inflammation in obesity. Arterioscler Thromb Vasc Biol. 2016:37:ATVBAHA. 116.308749.

169. Zeng Z, Li Y, Pan Y, Lan X, Song F, Sun J, Zhou K, Liu X, Ren X, Wang F. Cancer-derived exosomal miR-25-3p promotes pre-metastatic niche formation by inducing vascular permeability and angiogenesis. Nat Commun. 2018:9:1-14

170. Varga ZV, Kupai K, Szűcs G, Gáspár R, Pálóczi J, Faragó N, Zvara Á, Puskás LG, Rázga Z, Tiszlavicz LJJ. MicroRNA-25-dependent up-regulation of NADPH oxidase 4 (NOX4) mediates hypercholesterolemia-induced oxidative/nitrative stress and subsequent dysfunction in the heart. $J$ Mol Cell Cardiol. 2013;62:111-21.

171. Schürmann C, Rezende F, Kruse C, Yasar Y, Löwe O, Fork C, van de Sluis B, Bremer R, Weissmann N, Shah AM. The NADPH oxidase Nox4 has antiatherosclerotic functions. Eur Heart J. 2015;36:3447-56.

172. Schröder K, Zhang M, Benkhoff S, Mieth A, Pliquett R, Kosowski J, Kruse C, Lüdike $P$, Michaelis UR, Weissmann N. Nox4 is a protective reactive oxygen species generating vascular NADPH oxidase. Circulation research. 2012;112:267054.

173. Wang H-J, Huang $Y-L$, Shih $Y-Y$, Wu H-Y, Peng C-T, Lo W-YJ. MicroRNA146a decreases high glucose/thrombin-induced endothelial inflammation by inhibiting NAPDH oxidase 4 expression. Mediators Inflamm 2014:2014:379537.
174. Roos J, Enlund E, Funcke J-B, Tews D, Holzmann K, Debatin K-M, Wabitsch M, Fischer-Posovszky PJS. miR-146a-mediated suppression of the inflammatory response in human adipocytes. Sci Rep. 2016;6:38339.

175. Glick D, Barth S, Macleod K. Autophagy: cellular and molecular mechanisms. J Pathol. 2010;221:3-12.

176. Ren SY, Xu M. Role of autophagy in metabolic syndrome-associated heart disease. Biochim Biophys Acta. 2015;1852:225-31.

177. Ren J, Sowers JR, Zhang YJT. Metabolic stress, autophagy, and cardiovascular aging: from pathophysiology to therapeutics. Trends Endocrinol Metab. 2018;29:699-711.

178. Zhang Y, Huang B, Wang HY, Chang A, Zheng XFS. Emerging Role of MicroRNAs in mTOR Signaling. Cell Mol Life Sci. 2017;74:2613-25.

179. Chen K, Fan W, Wang X, Ke X, Wu G, Hu CJB. MicroRNA-101 mediates the suppressive effect of laminar shear stress on mTOR expression in vascular endothelial cells. Biochem Biophys Res Commun. 2012;427:138-42

180. Fornari F, Milazzo M, Chieco P, Negrini M, Calin GA, Grazi GL, Pollutri D, Croce CM, Bolondi L, Gramantieri LJC. MiR-199a-3p regulates mTOR and c-Met to influence the doxorubicin sensitivity of human hepatocarcinoma cells. Cancer Res. 2010;70:5184-93.

181. Wang J, Yang K, Zhou L, Wu Y, Zhu M, Lai X, Chen T, Feng L, Li M, Huang CJP. MicroRNA-155 promotes autophagy to eliminate intracellular mycobacteria by targeting Rheb. PLoS Pathog. 2013;9:e1003697.

182. Mentzel CMJ, Anthon C, Jacobsen MJ, Karlskov-Mortensen P, Bruun CS, Jørgensen CB, Gorodkin J, Cirera S, Fredholm MJP. Gender and obesity specific microRNA expression in adipose tissue from lean and obese pigs. PLoS One. 2015;10:e0131650.

183. Sun H-X, Zeng D-Y, Li R-T, Pang R-P, Yang H, Hu Y-L, Zhang Q, Jiang $Y$, Huang LY, Tang Y. Essential role of microRNA-155 in regulating endothelium-dependent vasorelaxation by targeting endothelial nitric oxide synthase. Hypertension. 2012;60:197301.

184. Gu N, You L, Shi C, Yang L, Pang L, Cui X, Ji C, Zheng W, Guo XJM. Expression of miR-199a-3p in human adipocytes is regulated by free fatty acids and adipokines. Molecular Medicine Reports. 2016;14:1180-6.

185. Tian X, Yu C, Shi L, Li D, Chen X, Xia D, Zhou J, Xu W, Ma C, Gu LJE. MicroRNA-199a-5p aggravates primary hypertension by damaging vascular endothelial cells through inhibition of autophagy and promotion of apoptosis. Exp Ther Med. 2018;16:595-602.

186. Higuchi C, Nakatsuka A, Eguchi J, Teshigawara S, Kanzaki M, Katayama A, Yamaguchi S, Takahashi N, Murakami K, Ogawa DJM. Identification of circulating miR-101, miR-375 and miR-802 as biomarkers for type 2 diabetes. Metabolism-Clinical and Experimental. 2015;64:489-97.

187. Smits M, Mir SE, Nilsson RJA, Stoop PM, Niers JM, Marquez VE, Cloos J, Breakefield XO, Krichevsky AM, Noske DPJP. Down-regulation of miR-101 in endothelial cells promotes blood vessel formation through reduced repression of EZH2. Plos ONE. 2011;6:e16282.

188. Ortega FJ, Moreno-Navarrete JM, Pardo G, Sabater M, Hummel M, Ferrer A, Rodriguez-Hermosa Jl, Ruiz B, Ricart W, Peral BJP. MiRNA expression profile of human subcutaneous adipose and during adipocyte differentiation. PLOS ONE. 2010;5:e9022.

189. Yang Z, Ming XF. mTOR signalling: the molecular interface connecting metabolic stress, aging and cardiovascular diseases. J Obesity Rev. 2012;13:58-68

190. Reineke DC, Müller-Schweinitzer E, Winkler B, Kunz D, Konerding MA, Grussenmeyer T, Carrel TP, Eckstein FS, Grapow M. Rapamycin impairs endothelial cell function in human internal thoracic arteries. Eur J Med Res. 2015:20:59.

191. Dong Q, Xing W, Su F, Liang X, Tian F, Gao F, Wang S, Zhang HJCP. Tetrahydroxystilbene glycoside improves microvascular endothelial dysfunction and ameliorates obesity-associated hypertension in obese zdf rats via inhibition of endothelial autophagy. Cell Physiol Biochem. 2017:43:293-307

192. Zhao G, Zhang J-G, Liu Y, Qin Q, Wang B, Tian K, Liu L, Li X, Niu Y, Deng S. miR-148b functions as a tumor suppressor in pancreatic cancer by targeting AMPKa1. Mol Cancer. 2013;12:83-93.

193. Kuwabara Y, Horie T, Baba O, Watanabe S, Nishiga M, Usami S, Izuhara M, Nakao T, Nishino T, Otsu K. MicroRNA-451 exacerbates lipotoxicity in cardiac myocytes and high-fat diet-induced cardiac hypertrophy in mice through suppression of the LKB1/AMPK pathway. Circ Res. 2014;114:304707. 
194. Shi C, Zhang M, Tong M, Yang L, Pang L, Chen L, Xu G, Chi X, Hong Q, $\mathrm{NiY}$. miR-148a is associated with obesity and modulates adipocyte differentiation of mesenchymal stem cells through Wnt signaling. Sci Rep. 2015;5:9930.

195. Chen M-B, Wei M-X, Han J-Y, Wu X-Y, Li C, Wang J, Shen W, Lu P-H. MicroRNA-451 regulates AMPK/mTORC1 signaling and fascin1 expression in HT-29 colorectal cancer. Cell Signal. 2014;26:102-9.

196. Ma L, Ma S, He H, Yang D, Chen X, Luo Z, Liu D, Zhu ZJHR. Perivascular fat-mediated vascular dysfunction and remodeling through the AMPK mTOR pathway in high-fat diet-induced obese rats. Hypertens Res. 2010;33:446.

197. Han F, Zhang S, Hou N, Wang D, Sun X. Irisin improves endothelial function in obese mice through the AMPK-eNOS pathway. Am J Physiol Heart Circ Physiol. 2015;12:7.

198. An M, Ryu D-R, Won Park J, Ha Choi J, Park E-M, Eun Lee K, Woo M, Kim MJC. ULK1 prevents cardiac dysfunction in obesity through autophagy-meditated regulation of lipid metabolism. Cardiovasc Res. 2017;113:1137-47.

199. Wu H, Wang F, Hu S, Yin C, Li X, Zhao S, Wang J, Yan XJC. MiR-20a and miR-106b negatively regulate autophagy induced by leucine deprivation via suppression of ULK1 expression in C2C12 myoblasts. Cell Signal. 2012;24:2179-86.

200. Pan B, Yi J, Song HJCB. Radiopharmaceuticals MicroRNA-mediated autophagic signaling networks and cancer chemoresistance. Cancer Biother Radiopharm. 2013;28:573-8.

201. Tschan MP, Jost M, Batliner J, Fey MF. The autophagy gene ULK1 plays a role in AML differentiation and is negatively regulated by the oncogenic MicroRNA 106a. Blood J. 2010;77:12.

202. Duan X, Zhang T, Ding S, Wei J, Su C, Liu H, Xu GJ. microRNA-17-5p modulates bacille calmette-guerin growth in RAW2647 cells by targeting ULK1. PLoS One. 2015;10:e0138011.

203. Pin A-L, Houle F, Guillonneau M, Paquet ER, Simard MJ, Huot JJA. miR-20a represses endothelial cell migration by targeting MKK3 and inhibiting p38 MAP kinase activation in response to VEGF. Angiogenesis. 2012;15:593-608.

204. Zhang Y, Yang L, Gao Y-F, Fan Z-M, Cai X-Y, Liu M-Y, Guo X-R, Gao C-L, Xia $Z-K$. MicroRNA-106b induces mitochondrial dysfunction and insulin resistance in $\mathrm{C} 2 \mathrm{C} 12$ myotubes by targeting mitofusin-2. Mol Cell Endocrinol. 2013;381:230-40.

205. Kumar S, Jo HJTFJ. Knockdown of mechanosensitive miRNA cluster-miR-106b $\sim 25$ decreases endothelial proliferation and prevents atherosclerosis in $\mathrm{ApoE}^{-} /^{-}$mice. Faseb J. 2016:30:161-165

206. Heneghan H, Miller N, McAnena O, O'brien T, Kerin MJ. Differential miRNA expression in omental adipose tissue and in the circulation of obese patients identifies novel metabolic biomarkers. J Clin Endocrinol Metab. 2011;96:E846-E850.

207. Yang S, Fan T, Hu Q, Xu W, Yang J, Xu C, Zhang B, Chen J, Jiang HJM. Downregulation of microRNA-17-5p improves cardiac function after myocardial infarction via attenuation of apoptosis in endothelial cells. Mol Genet Genomics. 2018;293:883-94.

208. Li S, Qiang Q, Shan H, Shi M, Gan G, Ma F, Chen BJL. MiR-20a and miR20 b negatively regulate autophagy by targeting RB1CC1/FIP200 in breast cancer cells. Life Sci. 2016;147:143-52.

209. Gentile AM, Lhamyani S, Coín-Aragüez L, Clemente-Postigo M, Oliva Olivera W, Romero-Zerbo SY, García-Serrano S, García-Escobar E, Zayed H, Doblado E. miR-20b, miR-296, and Let-7f Expression in human adipose tissue is related to obesity and type 2 diabetes. Obesity. 2018;72:12.

210. Wong P-F, Jamal J, Tong K-L, Khor E-S, Yeap C-E, Jong H-L, Lee S-T, Mustafa MR, Abubakar SJM. Deregulation of hsa-miR-20b expression in TNF-a-induced premature senescence of human pulmonary microvascular endothelial cells. Microvasc Res. 2017;114:26-33.

211. Yamakuchi MJB. Endothelial senescence and microRNA. Biomol Concepts. 2012;3:213-23.

212. Yi F, Hao Y, Chong $X$, Zhong WJE. Overexpression of microRNA-506-3p aggravates the injury of vascular endothelial cells in patients with hypertension by downregulating Beclin1 expression. Exp Ther Med. 2018;15:2844-50

213. Rahmouni K, Correia ML, Haynes WG, Mark ALJH. Obesity-associated hypertension: new insights into mechanisms. Hypertension. 2005;45:9-14.
214. Kotsis V, Stabouli S, Papakatsika S, Rizos Z. Parati GJHr. Mechanisms of obesity-induced hypertension. Hypertens Res. 2010;33:386.

215. Jiang SZ, Lu W, Zong XF, Ruan HY, Liu YJE. medicine t. Obesity and hypertension. Exp Ther Med. 2016;12:2395-9.

216. Menghini R, Casagrande V, Marino A, Marchetti V, Cardellini M, Stoehr R, Rizza S, Martelli E, Greco S, Mauriello AJC. MiR-216a: a link between endothelial dysfunction and autophagy. Cell Death Dis. 2014;5:e1029.

217. Brest P, Lassalle S, Hofman V, Bordone O, Tanga VG, Bonnetaud C, Moreilhon C, Rios G, Santini J, Barbry PJE. MiR-129-5p is required for histone deacetylase inhibitor-induced cell death in thyroid cancer cells. Endocr-Relat Cancer. 2011;18:711-9.

218. Geng Z, Xu F, Zhang YJA. MiR-129-5p-mediated Beclin-1 suppression inhibits endothelial cell autophagy in atherosclerosis. Am J Transl Res. 2016;8:1886

219. Milagro Fl, Miranda J, Portillo MP, Fernandez-Quintela A, Campión J, Martínez JAJP. High-throughput sequencing of microRNAs in peripheral blood mononuclear cells: identification of potential weight loss biomarkers. PLoS One. 2013;8:e54319.

220. Korkmaz G, Le Sage C, Tekirdag KA, Agami R, Gozuacik DJA. miR-376b controls starvation and mTOR inhibition-related autophagy by targeting ATG4C and BECN1. Autophagy. 2012;8:165-76.

221. Mizushima N, Yoshimori T, Ohsumi YJA. The role of Atg proteins in autophagosome formation. Annu Rev Cell Dev Biol. 2011;27:107-32.

222. Codogno P, Meijer AJJ. Atg5: more than an autophagy factor. Nat Cell Biol. 2006;8:1045.

223. Yang J, He Y, Zhai N, Ding S, Li J, Peng Z. MicroRNA-181a inhibits autophagy by targeting Atg5 in hepatocellular carcinoma. Front Biosci (Landmark Ed). 2018;23:388-96.

224. Liu G, Li Y, Gao XJE. microRNA-181a is upregulated in human atherosclerosis plaques and involves in the oxidative stress-induced endothelial cell dysfunction through direct targeting Bcl-2. Eur Rev Med Pharmacol Sci. 2016;20:3092-100.

225. Li H, Chen X, Guan L, Qi Q, Shu G, Jiang Q, Yuan L, Xi Q, Zhang YJP. MiRNA-181a regulates adipogenesis by targeting tumor necrosis factor-a (TNF-a) in the porcine model. PLoS One. 2013;8:e71568.

226. Zhou B, Li C, Qi W, Zhang Y, Zhang F, Wu J, Hu Y, Wu D, Liu Y, Yan TJD. Downregulation of miR-181a upregulates sirtuin-1 (SIRT1) and improves hepatic insulin sensitivity. Diabetologia. 2012;55:2032-43.

227. Huang Y, Guerrero-Preston R, Ratovitski EA. Phospho- $\triangle$ Np63adependent regulation of autophagic signaling through transcription and micro-RNA modulation. Cell Cycle. 2012;11:1247-59.

228. Jones A, Danielson KM, Benton MC, Ziegler O, Shah R, Stubbs RS, Das $\mathrm{S}$, Macartney-Coxson DJO. miRNA signatures of insulin resistance in obesity. Obesity (Silver Spring). 2017;25:1734-44.

229. Lee JS, Song DW, Park JH, Kim JO, Cho C, Kim DHJ. miR-374 promotes myocardial hypertrophy by negatively regulating vascular endothelial growth factor receptor-1 signaling. BMB Rep. 2017;50:208.

230. Gozuacik D, Akkoc Y, Ozturk DG. Autophagy-regulating microRNAs and cancer. Front Oncol. 2017;7:65.

231. Khalyfa A, Kheirandish-Gozal L, Khalyfa AA, Philby MF, Alonso-Álvarez ML, Mohammadi M, Bhattacharjee R, Terán-Santos J, Huang L, Andrade JJA. Circulating plasma extracellular microvesicle microRNA cargo and endothelial dysfunction in children with obstructive sleep apnea. Am J Respir Crit Care Med. 2016;194:1116-26.

232. Torisu K, Singh KK, Torisu T, Lovren F, Liu J, Pan Y, Quan A, Ramadan A, Al-Omran M, Pankova NJAC. Intact endothelial autophagy is required to maintain vascular lipid homeostasis. Aging Cell. 2016;15:187-91.

233. Wang C, Zhang ZZ, Yang W, Ouyang ZH, Xue JB, Li XL, Zhang J, Chen WK, Yan YG, Wang W. MiR-210 facilitates ECM degradation by suppressing autophagy via silencing of ATG7 in human degenerated NP cells. Biomed Pharmacother. 2017;93:470-9.

234. Wang K, Liu CY, Zhou LY, Wang JX, Wang M, Zhao B, Zhao WK, Xu SJ, Fan LH, Zhang XJJN. APF IncRNA regulates autophagy and myocardial infarction by targeting miR-188-3p. Nat Commun. 2015;6:6779.

235. Zeng Y, Huo G, Mo Y, Wang W, Chen H. MIR137 regulates starvation-induced autophagy by targeting ATG7. J Mol Neurosci. 2015;56:815-21.

236. Zhang X-F, Yang Y, Yang X-Y, Tong QJT. MiR-188-3p upregulation results in the inhibition of macrophage proinflammatory activities and atherosclerosis in ApoE-deficient mice. Thromb Res. 2018;171:55-61. 
237. Tucci A, Ciaccio C, Scuvera G, Esposito S, Milani DJM. MIR137 is the key gene mediator of the syndromic obesity phenotype of patients with 1p213 microdeletions. Mol Cytogenet. 2016;9:80.

238. Peng H-Y, Li H-P, Li MQJM. High glucose induces dysfunction of human umbilical vein endothelial cells by upregulating miR-137 in gestational diabetes mellitus. Microvasc Res. 2018;118:90-100.

239. Sun KT, Chen MY, Tu MG, Wang IK, Chang SS, Li C. MicroRNA-20a regulates autophagy related protein-ATG16L1 in hypoxia-induced osteoclast differentiation. Bone. 2015;73:145-53.

240. Gan J, Cai Q, Qu Y, Zhao F, Wan C, Luo R, Mu DJS. miR-96 attenuates status epilepticus-induced brain injury by directly targeting Atg7 and Atg16L1. Sci Rep. 2017;7:10270.

241. Yang W-M, Min K-H, Lee WJPO. Induction of miR-96 by dietary saturated fatty acids exacerbates hepatic insulin resistance through the suppression of INSR and IRS-1. PLOS ONE. 2016;11:e0169039.

242. Kim S, Hata A, Kang H. Down-regulation of mir-96 by bone morphogenetic protein signaling is critical for vascular smooth muscle cell phenotype modulation. J Cell Biochem. 2014;115:889-95.

243. Xiao J, Zhu X, He B, Zhang Y, Kang B, Wang Z, Ni XJ. MiR-204 regulates cardiomyocyte autophagy induced by ischemia-reperfusion through LC3-II. J Biomed Sci. 2011;18:35.

244. Meenhuis $A$, van Veelen PA, de Looper $H$, van Boxtel $N$, van den Berge IJ, Sun SM, Taskesen E, Stern P, de Ru AH, van Adrichem AJJB. MiR17/20/93/106 promote hematopoietic cell expansion by targeting sequestosome 1-regulated pathways in mice. Blood. 2011;118:916-25.

245. Chamorro-Jorganes A, Lee MY, Araldi E, Landskroner-Eiger S, FernándezFuertes M, Sahraei M, Rey M, Van Solingen C, Yu J, Fernández-Hernando CJC. VEGF-induced expression of miR-17-92 cluster in endothelial cells is mediated by ERK/ELK1 activation and regulates angiogenesis. Circ Res. 2016;118:38-47.

246. Cioffi M, Vallespinos-Serrano M, Trabulo SM, Fernandez-Marcos PJ, Firment AN, Vazquez BN, Vieira CR, Mulero F, Camara JA, Cronin UPJC. MiR-93 controls adiposity via inhibition of Sirt7 and Tbx3. Cell Rep. 2015;12:1594-605.

247. Kuosmanen SM, Kansanen E, Kaikkonen MU, Sihvola V, Pulkkinen K, Jyrkkänen H-K, Tuoresmäki P, Hartikainen J, Hippeläinen M, Kokki HJ. NRF2 regulates endothelial glycolysis and proliferation with miR-93 and mediates the effects of oxidized phospholipids on endothelial activation. Nucleic Acids Res. 2017;46:1124-38.

248. Long J, Wang Y, Wang W, Chang BH, Danesh FRJ. Identification of microRNA-93 as a novel regulator of vascular endothelial growth factor in hyperglycemic conditions. J Biol Chem. 2010;285:23457-65.

249. Shen H-M, Mizushima NJT. At the end of the autophagic road: an emerging understanding of lysosomal functions in autophagy. Trends Biochem Sci. 2014;39:61-71.

250. Xie Z, Klionsky D. Autophagosome formation: core machinery and adaptations. J Nature cell biology. 2007;9:1102.

251. Su Z, Yang Z, Xu Y, Chen Y, Yu QJO. MicroRNAs in apoptosis, autophagy and necroptosis. Oncotarget. 2015;6:8474.

252. Mizunoe Y, Sudo Y, Okita N, Hiraoka H, Mikami K, Narahara T, Negishi A, Yoshida M, Higashibata R, Watanabe SJA. Involvement of lysosomal dysfunction in autophagosome accumulation and early pathologies in adipose tissue of obese mice. Autophagy. 2017;13:642-53.

253. Patschan S, Chen J, Gealekman O, Krupincza K, Wang M, Shu L, Shayman JA, Goligorsky RP. Mapping mechanisms and charting the time course of premature cell senescence and apoptosis: lysosomal dysfunction and ganglioside accumulation in endothelial cells. Am J Physiol Renal Physiol. 2008;294:F100-9.

254. Kim Y, Kang Y-S, Lee N-Y, Kim KY, Hwang YJ, Kim H-W, Rhyu IJ, Her S, Jung M-K, Kim SJA. Uvrag targeting by Mir125a and Mir351 modulates autophagy associated with Ewsr 1 deficiency. Autophagy. 2015;11:796-811.

255. Li X, Yao N, Zhang J, Liu ZJM. MicroRNA-125b is involved in atherosclerosis obliterans in vitro by targeting podocalyxin. Molecular Medicine Reports. 2015;12:561-8.

256. Rippe C, Blimline M, Magerko KA, Lawson BR, LaRocca TJ, Donato AJ, Seals DRJE. MicroRNA changes in human arterial endothelial cells with senescence: relation to apoptosis, eNOS and inflammation. Exp Gerontol. 2012;47:45-51.
257. Zhang Y, Liu Y, Zhang H, Wang M, Zhang JJB. Mmu-miR-351 attenuates the survival of cardiac arterial endothelial cells through targeting STAT3 in the atherosclerotic mice. Biochem Bioph Res Co. 2015;468:300-5.

258. Chandran PA, Keller A, Weinmann L, Adel Seida A, Braun M, Andreev K, Fischer B, Horn E, Schwinn S, Junker MJJ. The TGF-B-inducible miR-23a cluster attenuates IFN- $\gamma$ levels and antigen-specific cytotoxicity in human CD8 + T cells. J Leukoc Biol. 2014;96:633-45.

259. Okato A, Goto Y, Kurozumi A, Kato M, Kojima S, Matsushita R, Yonemori M, Miyamoto K, Ichikawa T, Seki NJI. Direct regulation of LAMP1 by tumor-suppressive microRNA-320a in prostate cancer. Int J Oncol. 2016;49:111-22.

260. Yang S, Ye Z-M, Chen S, Luo X-Y, Chen S-L, Mao L, Li Y, Jin H, Yu C, Xiang F. MicroRNA-23a-5p promotes atherosclerotic plaque progression and vulnerability by repressing ATP-binding cassette transporter A1/G1 in macrophages. J Mol Cell Cardiol. 2018;123:139-49.

261. Han H, Qu G, Han C, Wang Y, Sun T, Li F, Wang J, Luo S. MiR-34a, miR-21 and miR-23a as potential biomarkers for coronary artery disease: a pilot microarray study and confirmation in a 32 patient cohort. Exp Mol Med. 2015:47:e138.

262. Karolina DS, Tavintharan S, Armugam A, Sepramaniam S, Pek SLT, Wong MT, Lim SC, Sum CF, Jeyaseelan KCE. Circulating miRNA profiles in patients with metabolic syndrome. J Clin Endocrinol Metab. 2012;97:E2271-6.

263. Chen C, Wang Y, Yang S, Li H, Zhao G, Wang F, Yang L, Wang DW. MiR320 a contributes to atherogenesis by augmenting multiple risk factors and down-regulating SRF. J Cell Mol Med. 2015;19:970-85.

264. Bao L, Lv L, Feng J, Chen Y, Wang X, Han S, Zhao HJD. miR-487b-5p regulates temozolomide resistance of lung cancer cells through LAMP2-medicated autophagy. DNA Cell Biol. 2016;35:385-92.

265. Nguyen HT, Noguchi S, Sugie K, Matsuo Y, Nguyen CT, Koito H, Shiojima I, Nishino I, Tsukaguchi HJS. Small-vessel vasculopathy due to aberrant autophagy in LAMP-2 deficiency. Sci Rep. 2018;8:3326.

266. Soh J, labal J, Queiroz J, Fernandez-Hernando C, Hussain MMJ. MicroRNA-30c reduces hyperlipidemia and atherosclerosis in mice by decreasing lipid synthesis and lipoprotein secretion. Nat Med. 2013;19:892.

267. Lou Z, Casali P, Xu ZJF. Regulation of B cell differentiation by intracellular membrane-associated proteins and microRNAs: role in the antibody response. Front Immunol. 2015;6:537.

268. Miranda K, Yang X, Bam M, Murphy EA, Nagarkatti PS, Nagarkatti MJIO. MicroRNA-30 modulates metabolic inflammation by regulating Notch signaling in adipose tissue macrophages. Int J Obes (Lond). 2018:42:1140

269. Yin Z, Zhao Y, He M, Li H, Fan J, Nie X, Yan M, Chen C, Wang DW. MiR$30 \mathrm{C} / \mathrm{PGC}-1 \beta$ protects against diabetic cardiomyopathy via PPARa. Cardiovasc Diabetol. 2019:18:1-15.

270. Han J, Pan XY, Xu Y, Xiao Y, An Y, Tie L, Pan Y, Li XJJA. Curcumin induces autophagy to protect vascular endothelial cell survival from oxidative stress damage. Autophagy. 2012;8:812-25.

271. Kondkar A, Bray M, Leal S, Nagalla S, Liu D, Jin Y, Dong J, Ren Q, Whiteheart S, Shaw CJJ. VAMP8/endobrevin is overexpressed in hyperreactive human platelets: suggested role for platelet microRNA. J Thromb Haemost. 2010:8:369-78.

272. Huang J, Yang Y, Fang F, Liu K. MALAT1 modulates the autophagy of retinoblastoma cell through miR-124-mediated stx17 regulation. J Cell Biochem. 2018;119:3853-63.

273. Caruso P, Dunmore BJ, Schlosser K, Schoors S, Dos Santos C, PerezIratxeta C, Lavoie JR, Zhang H, Long L, Flockton ARJC. Identification of microRNA-124 as a major regulator of enhanced endothelial cell glycolysis in pulmonary arterial hypertension via PTBP1 (polypyrimidine tract binding protein) and pyruvate kinase M2. Circulation. 2017;136:2451-67.

274. Zhang H, Zhang S, Zhang J, Liu D, Wei J, Fang W, Zhao W, Chen Y, Shang DJJ. ZO-1 expression is suppressed by GM-CSF via miR-96/ERG in brain microvascular endothelial cells. J Cerebr Blood F Met. 2018;38:809-22.

275. Wang S, Deng L, Chen H, Su Z, Ye S, Xu WJE. MiR-124 affects the apoptosis of brain vascular endothelial cells and ROS production through regulating PI3K/AKT signaling pathway. Eur Rev Med Pharmaco. 2018;22:498-505. 
276. Gibbings D, Mostowy S, Jay F, Schwab Y, Cossart P, Voinnet OJN. Selective autophagy degrades DICER and AGO2 and regulates miRNA activity. Nat Cell Biol. 2012;14:1314.

277. Ellgaard L, Helenius AJN. Quality control in the endoplasmic reticulum. Nat Rev Mol Cell Biol. 2003;4:181.

278. Kozutsumi Y, Segal M, Normington K, Gething M-J, Sambrook JJN. The presence of malfolded proteins in the endoplasmic reticulum signals the induction of glucose-regulated proteins. Nature. 1988;332:462.

279. Gardner BM, Walter PJS. Unfolded proteins are Ire1-activating ligands that directly induce the unfolded protein response. Science. 2011;333:1891-4.

280. Xu C, Bailly-Maitre B, Reed JCJ. Endoplasmic reticulum stress: cell life and death decisions. J Clin Invest. 2005;115:2656-64.

281. Özcan U, Cao Q, Yilmaz E, Lee A-H, Iwakoshi NN, Özdelen E, Tuncman G, Görgün C, Glimcher LH, Hotamisligil GSJS. Endoplasmic reticulum stress links obesity, insulin action, and type 2 diabetes. Science. 2004;306:457-61.

282. Ozcan L, Tabas IJA. Role of endoplasmic reticulum stress in metabolic disease and other disorders. Annu Rev Med. 2012;63:317-28.

283. Shah D, Romero F, Guo Z, Sun J, Li J, Kallen CB, Naik UP, Summer RJA. Obesity-induced endoplasmic reticulum stress causes lung endothelial dysfunction and promotes acute lung injury. Am J Respir Cell Mol Biol. 2017;57:204-15.

284. Malhi HJ. MicroRNAs in ER stress: divergent roles in cell fate decisions. Curr Pathobiol Rep. 2014;2:117-22.

285. Lee ASJM. The ER chaperone and signaling regulator GRP78/BiP as a monitor of endoplasmic reticulum stress. Methods. 2005;35:373-81.

286. Leonard A, Grose V, Paton AW, Paton JC, Yule DI, Rahman A, Fazal FJS. Selective Inactivation of Intracellular BiP/GRP78 attenuates endothelial inflammation and permeability in acute lung injury. Sci Rep. 2019;9:2096.

287. Philippova M, Ivanov D, Joshi MB, Kyriakakis E, Rupp K, Afonyushkin T, Bochkov V, Erne P, Resink TJJM. Identification of proteins associating with glycosylphosphatidylinositol-anchored T-cadherin on the surface of vascular endothelial cells: role for Grp78/BiP in T-cadherindependent cell survival. Mol Cell Biol. 2008;28:4004-17.

288. Su S, Chang Y, Andreu-Vieyra C, Fang J, Yang Z, Han B, Lee A, Liang GJO. miR-30d, miR-181a and miR-199a-5p cooperatively suppress the endoplasmic reticulum chaperone and signaling regulator GRP78 in cancer. Oncogene. 2013;32:4694.

289. Li G, Luna C, Qiu J, Epstein DL, Gonzalez PJI. Role of miR-204 in the regulation of apoptosis, endoplasmic reticulum stress response, and inflammation in human trabecular meshwork cells. Invest Ophthalmol Vis Sci. 2011;52:2999-3007.

290. Xu G, Chen J, Jing G, Grayson TB, Shalev AJM. miR-204 targets PERK and regulates UPR signaling and $\beta$-cell apoptosis. Mol Endocrinol. 2016:30:917-24.

291. Huang $H$, Jing G, Wang JJ, Sheibani N, Zhang SX. ATF4 is a novel regulator of $\mathrm{MCP}-1$ in microvascular endothelial cells. J Inflamm. 2015;12:31.

292. Oskolkova OV, Afonyushkin T, Leitner A, von Schlieffen E, Gargalovic PS, Lusis AJ, Binder BR, Bochkov VNJB. ATF4-dependent transcription is a key mechanism in VEGF up-regulation by oxidized phospholipids: critical role of oxidized $\mathrm{sn}-2$ residues in activation of unfolded protein response. Blood. 2008;112:330-9.

293. Wang X, Guo B, Li Q, Peng J, Yang Z, Wang A, Li D, Hou Z, Lv K, Kan GJ. miR-214 targets ATF4 to inhibit bone formation. Nat Med. 2013:19:93.

294. He L, Tang M, Xiao T, Liu H, Liu W, Li G, Zhang F, Xiao Y, Zhou Z, Liu F. Obesity-associated miR-199a/214 cluster inhibits adipose browning via PRDM16-PGC-1 a transcriptional network. J Diabetes. 2018;67:2585-600.

295. Wang S, Liao J, Huang J, Yin H, Yang W, Hu M. miR-214 and miR-126 were associated with restoration of endothelial function in obesity after exercise and dietary intervention. J Appl Biomed. 2018;16:34-9.

296. Afonyushkin T, Oskolkova OV, Bochkov VNJA. Permissive role of miR-663 in induction of VEGF and activation of the ATF4 branch of unfolded protein response in endothelial cells by oxidized phospholipids. Atherosclerosis. 2012;225:50-5.

297. Laffont B, Rayner KJJC. MicroRNAs in the pathobiology and therapy of atherosclerosis. Can J Cardiol. 2017;33:313-24.
298. Ni C-W, Qiu H, Jo H, Physiology C. MicroRNA-663 upregulated by oscillatory shear stress plays a role in inflammatory response of endothelial cells. Am J Physiol Heart Circ Physiol. 2011;300:1762-9.

299. Nishitoh HJB. CHOP is a multifunctional transcription factor in the ER stress response. J Biochem. 2012;151:217-9.

300. Chitnis NS, Pytel D, Bobrovnikova-Marjon E, Pant D, Zheng H, Maas NL, Frederick B, Kushner JA, Chodosh LA, Koumenis CJM. miR-211 is a prosurvival microRNA that regulates chop expression in a PERK-dependent manner. Mol Cell. 2012:48:353-64.

301. Jiang Y, Wang H-Y, Li Y, Guo S-H, Zhang L, Cai J-J. Peripheral blood miRNAs as a biomarker for chronic cardiovascular diseases. Scientific Reports. 2014:4:5026.

302. Cimellaro A, Perticone M, Fiorentino T, Sciacqua A, Hribal MJN. Role of endoplasmic reticulum stress in endothelial dysfunction. Nutr Metab Cardiovasc Dis. 2016;26:863-71.

303. Maurel M, Dejeans N, Taouji S, Chevet E, Grosset CFJR. MicroRNA1291-mediated silencing of IRE1 a enhances Glypican-3 expression. RNA. 2013:19:778-88.

304. Peng L, Chun-guang Q, Bei-fang L, Xue-zhi D, Zi-hao W, Yun-fu L, Yan-ping D, Yang-gui L, Wei-guo L, Tian-yong HJD. Clinical impact of circulating miR-133, miR-1291 and miR-663b in plasma of patients with acute myocardial infarction. Diagn Pathol. 2014;9:89.

305. Zhu J, Su X, Li G, Chen J, Tang B, Yang YJAA. The incidence of acute myocardial infarction in relation to overweight and obesity: a meta-analysis. Arch Med Sci. 2014;10:855.

306. Bhagat KJC. Endothelial function and myocardial infarction. Cardiovasc Res. 1998:39:312-7.

307. Duan Q, Wang X, Gong W, Ni L, Chen C, He X, Chen F, Yang L, Wang P, Wang DWJP. ER stress negatively modulates the expression of the miR199a/214 cluster to regulates tumor survival and progression in human hepatocellular cancer. Plos One. 2012;7:e31518.

308. Byrd AE, Aragon IV, Brewer JWJB. MicroRNA-30c-2* limits expression of proadaptive factor XBP1 in the unfolded protein response. J Cell Biol. 2012;196:689-98.

309. Chhabra R, Dubey R, Saini NJR. Gene expression profiling indicate role of ER stress in miR-23a 27a-24-2 cluster induced apoptosis in HEK293T cells. RNA Biol. 2011;8:648-64.

310. Chen Y, Zhang F, Zhao Y, He K, Zheng X, Pan Y, Shao D, Shang P, Yang $Y$, Zhang DJO. Obesity-associated mir-27a upregulation promotes hepatocellular carcinoma metastasis through suppressing sFrP1. Oncotargets Ther. 2018;11:3281

311. Alvarez ML, Khosroheidari M, Eddy E, Done SCJA. MicroRNA-27a decreases the level and efficiency of the LDL receptor and contributes to the dysregulation of cholesterol homeostasis. Atherosclerosis. 2015;242:595-604.

312. Oglesby IK, Agrawal R, Mall MA, McElvaney NG, Greene CMJ. miRNA-221 is elevated in cystic fibrosis airway epithelial cells and regulates expression of ATF6. Mol Cell Pediatrics. 2015;2:1.

313. Meerson A, Traurig M, Ossowski V, Fleming J, Mullins M, Baier L. Human adipose microRNA-221 is upregulated in obesity and affects fat metabolism downstream of leptin and TNF-a. Diabetologia. 2013;56:1971-9.

314. Xue Y, Wei Z, Ding H, Wang Q, Zhou Z, Zheng S, Zhang Y, Hou D, Liu Y, Zen KJA. MicroRNA-19b/221/222 induces endothelial cell dysfunction via suppression of PGC-1a in the progression of atherosclerosis. Atherosclerosis. 2015;241:671-81.

315. Brettfeld C, Maver A, Aumuller E, Peterlin B, Haslberger AGJJ. MicroRNAs Responsible for Inflammation in Obesity. J Endocrinol Metab. 2017:7:77-85

316. Costantino S, Akhmedov A, Melina G, Mohammed S, Wijnen W, Othman A, Hornemann T, Volpe M, Sinatra R, Camici G. 1431 Modulation of JunD by miR-494-3p causes intra-myocardial lipid accumulation and obesity cardiomyopathy: a study in mice and humans. Eur Heart J. 2018;39(ehy565):1431.

317. Liu K, Xuekelati S, Zhang Y, Yin Y, LiY, Chai R, Li X, Peng Y, Wu J, Guo XJB. Expression levels of atherosclerosis-associated miR-143 and miR-145 in the plasma of patients with hyperhomocysteinaemia. BMC Cardiovasc Disord. 2017;17:163.

318. Santovito D, Mandolini C, Marcantonio P, De Nardis V, Bucci M, Paganelli C, Magnacca F, Ucchino S, Mastroiacovo D, Desideri GJ. Overexpression of microRNA-145 in atherosclerotic plaques from hypertensive patients. Expert Opin Ther Targets. 2013;17:217-23. 
319. Wezel A, Welten SM, Razawy W, Lagraauw HM, de Vries MR, Goossens EA, Boonstra MC, Hamming JF, Kandimalla ER, Kuiper JJA. Inhibition of microRNA-494 reduces carotid artery atherosclerotic lesion development and increases plaque stability. Ann Surg. 2015;262:841-8.

320. Maurel M, Chevet EJ-CP. Endoplasmic reticulum stress signaling: the microRNA connection. Am J Physiol Cell Physiol. 2013:304:C1117-C1126.

321. Beg MS, Brenner AJ, Sachdev J, Borad M, Kang YK, Stoudemire J, Smith S, Bader AG, Kim S, Hong DS. Phase I study of MRX34, a liposomal miR34a mimic, administered twice weekly in patients with advanced solid tumors. Invest New Drugs. 2017;35:180-8.

322. Heller KN, Mendell JT, Mendell JR, Rodino-Klapac LR. MicroRNA-29 overexpression by adeno-associated virus suppresses fibrosis and restores muscle function in combination with micro-dystrophin. JCI Insight. 2017;2:2.

323. Israelow B, Mullokandov G, Agudo J, Sourisseau M, Bashir A, Maldonado AY, Dar AC, Brown BD, Evans MJ. Hepatitis C virus genetics affects miR122 requirements and response to miR-122 inhibitors. Nat Commun. 2014,5:5408.

\section{Publisher's Note}

Springer Nature remains neutral with regard to jurisdictional claims in published maps and institutional affiliations.
Ready to submit your research? Choose BMC and benefit from:

- fast, convenient online submission

- thorough peer review by experienced researchers in your field

- rapid publication on acceptance

- support for research data, including large and complex data types

- gold Open Access which fosters wider collaboration and increased citations

- maximum visibility for your research: over 100M website views per year

At BMC, research is always in progress.

Learn more biomedcentral.com/submissions 